\title{
SEEKING MIRRORS: A STUDY OF STUDENT SELECTION AND USE OF CULTURALLY RELEVANT TEXTS
}

By Suzanne V. Kromer

\author{
A thesis \\ submitted in partial fulfillment \\ of the requirements for the degree of \\ Master of Arts in Education, Literacy \\ Boise State University
}

December 2017 
(C) 2017

Suzanne V. Kromer

ALL RIGHTS RESERVED 


\title{
BOISE STATE UNIVERSITY GRADUATE COLLEGE
}

\section{DEFENSE COMMITTEE AND FINAL READING APPROVALS}

of the thesis submitted by

\author{
Suzanne V. Kromer
}

Thesis Title: Seeking Mirrors: A Study of Student Selection and Use of Culturally Relevant Texts

Date of Final Oral Examination: $\quad 27$ September 2017

The following individuals read and discussed the thesis submitted by student Suzanne V. Kromer, and they evaluated her presentation and response to questions during the final oral examination. They found that the student passed the final oral examination.

Roger Stewart, Ph.D. Chair, Supervisory Committee

Amber Warrington, Ph.D. Member, Supervisory Committee

Stanley Steiner, Ph.D. Member, Supervisory Committee

The final reading approval of the thesis was granted by Roger Stewart, Ph.D., Chair of the Supervisory Committee. The thesis was approved by the Graduate College. 


\section{ACKNOWLEDGEMENTS}

I would like to thank my advisor, Dr. Roger Stewart, for his assistance through this process, as well as the guidance from my committee members, Dr. Amber Warrington and Dr. Stan Steiner. Further thanks goes out to the extended members of the

literacy department at Boise State, who offered encouragement and help at every step of the way. Lastly, to Ryan and Maya, who helped me see this endeavor through. 


\begin{abstract}
Despite a growing body of work involving culturally relevant pedagogy, methods for selecting culturally relevant literature, or involving students in the selection process, are poorly understood. The objective of this qualitative study of a seventh grade language arts classroom was to explore a process for students to assess and select culturally relevant literature. This study also probed how the implementation of culturally relevant literature impacted achievement, engagement, and interest. The resulting process utilized cultural relevancy rubrics and book previews, which led to a majority of students finding a culturally relevant novel. During the literature unit, student achievement rates were maintained, and positive shifts in engagement and interest were found. Results of this study emphasize the importance of text accessibility and text knowledge when guiding students in selecting novels for cultural relevancy.
\end{abstract}


TABLE OF CONTENTS

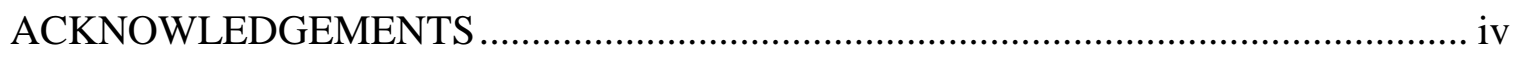

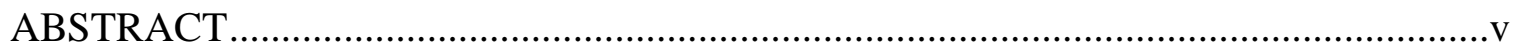

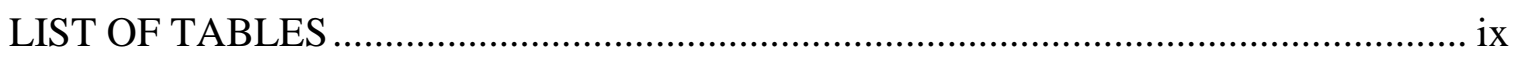

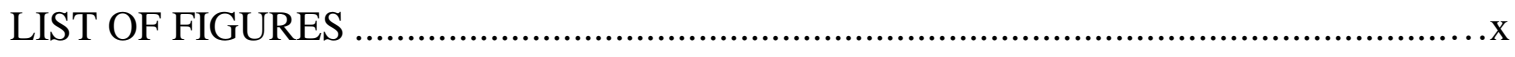

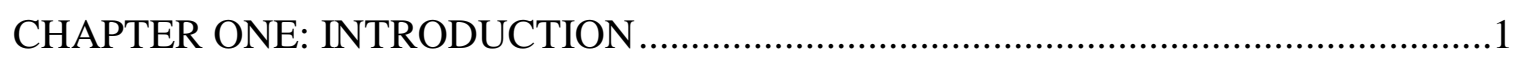

A Look Into Culturally Relevant Pedagogy..........................................................

Theoretical Framework ……………............................................................

Statement of the Problem.................................................................................

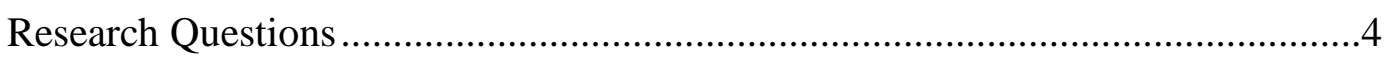

Phase I: Assessing Cultures \& Curriculum Representation...........................5

Phase II: Selection \& Implementation .......................................................

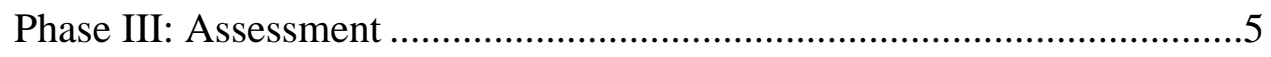

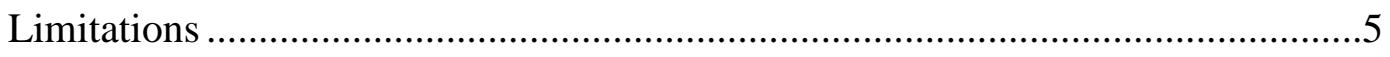

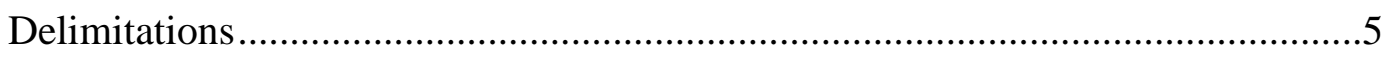

CHAPTER TWO: LITERATURE REVIEW …………….......................................

Determining Cultural Relevancy in Literature ……….........................................

How Students Use Cultural Relevancy with Texts ................................................

Impacts on Engagement, Personal Connections, and Critical Thinking ................11

Reading Comprehension With Culturally Relevant Texts.....................................16 
Context \& Participants

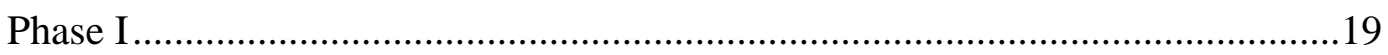

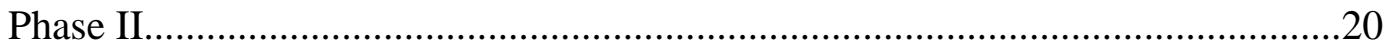

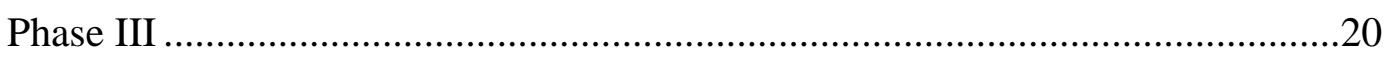

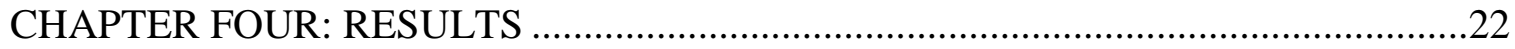

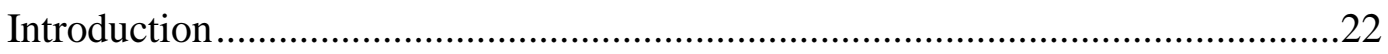

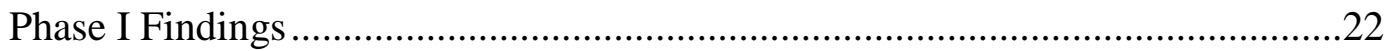

Student Identification of Significant Culturesis[ep] .................................22

Do Students Assess Books for Cultural Relevancy? .............................24

Cultural Representation in Existing Curriculum..................................26

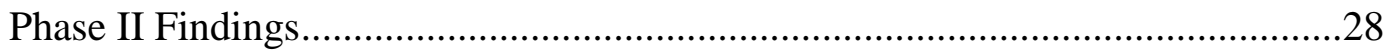

siepiThe Process to Assess and Select Culturally Relevant Literature .........28

Accuracy of Student Relevancy Predictions .........................................33

Student Assessment of Novel Relevancy ...........................................35

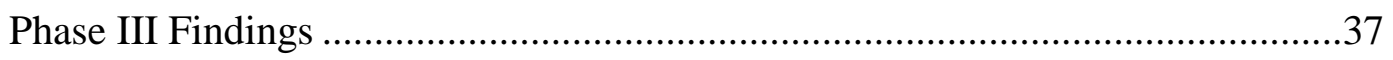

Culturally Relevant Novel Use Impact on Achievement........................37

Culturally Relevant Novel Use Impact on Engagement .........................37

Unit Impact on Interest in Culturally Relevant Texts ..........................40

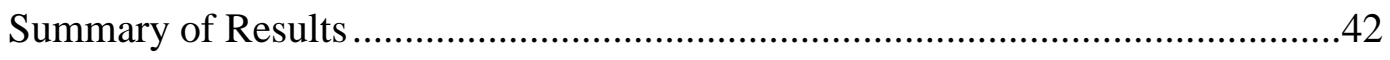

CHAPTER FIVE: DISCUSSION \& RECOMMENDATIONS ..................................44

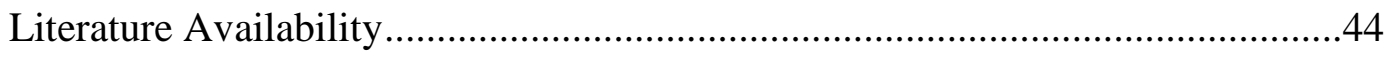

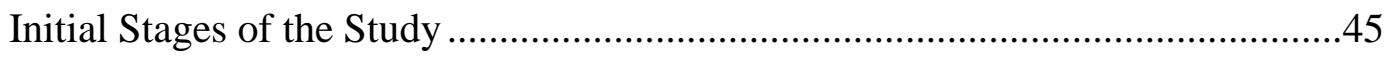




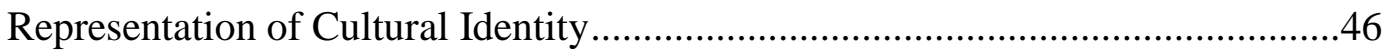

The Selection Process and Relevancy Rubrics .....................................................47

Critical Literacy with Culturally Relevant Novels ...............................................48

Data Collection Methods ............................................................................49

Engagement and Achievement ………………………...................................50

Preferences and Interest in Culturally Relevant Literature ....................................51

Data for Future Research ..............................................................................53

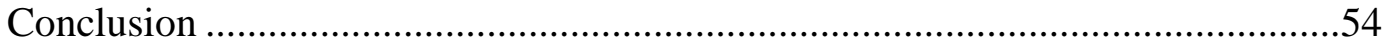

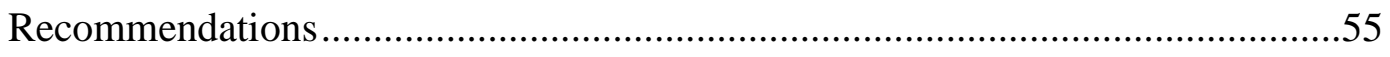

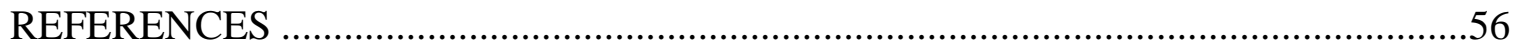

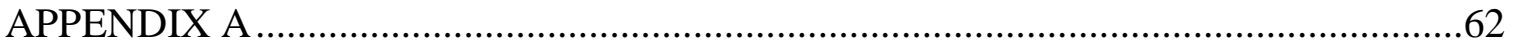

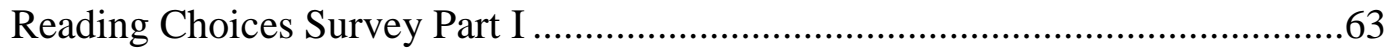

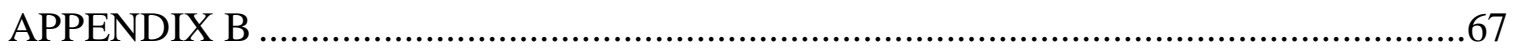

Reading Choices Survey Part II .....................................................................68

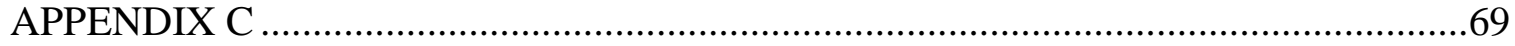

Curriculum Critique Chart …………………....................................................

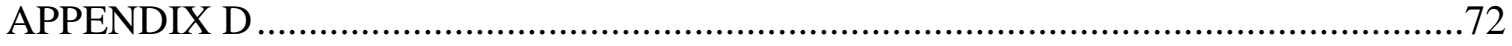

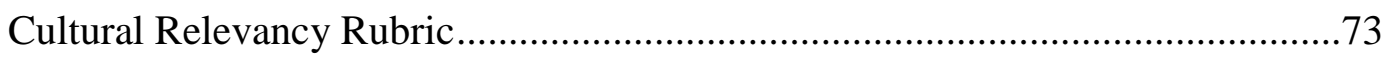

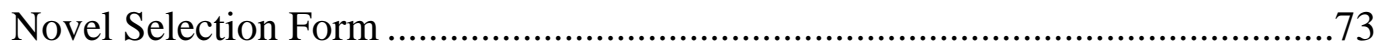

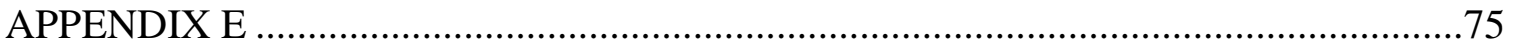

Novels Used in Culturally Relevant Literature Unit.............................................76

Additional Books Cited in Literature for Cultural Relevancy .....................77 


\section{LIST OF TABLES}

Table 1.1 Cultural Elements Pre-Post Comparison......................26

Table 1.2 Positive Shifts in Cultural Preferences..........................42 


\section{LIST OF FIGURES}

Figure 1: Example of a Completed Curriculum Critique ………………………...... 28

Figure 2: $\quad$ Comparison of Student Prediction Vs. Actual Relevancy ......................... 34

Figure 3: Comparison of Relevancy by Survey Response ……………………….... 37 


\section{CHAPTER ONE: INTRODUCTION}

\section{A Look Into Culturally Relevant Pedagogy}

Over the past 30 years, educators have been working towards Ladson-Billings (1995) call to action for creating culturally relevant pedagogy. Though it has been labeled and reiterated in a multitude of ways (Cazden and Leggett, 1981; Erickson and Mohatt, 1982; Irvine, 1990; Au And Kawakami, 1994; Ladson-Billings, 2014), culturally relevant pedagogy establishes itself on the basis of cultural diversity, with educators demonstrating care within purposeful learning communities, engaging in instructional methods that respond to ethnic diversity, and using culturally diverse content in the curriculum (Gay, 2002). Rather than solely emphasize mainstream ideals and schema as reflected in traditional curriculum (Heath, 1991), culturally relevant teaching integrates non-mainstream features into the curriculum based on the community of students. This

community is becoming increasingly diverse in the United States; the U.S. Department of Education projects minorities will become the majority of learners in 2018, with a $32 \%$ increase of Hispanic students from 2011 to 2023 (Hussar \& Bailey, 2016). Culturally relevant or culturally sustaining (Ladson-Billings, 2014) classrooms respond to this reality by continually reshaping the word of the classroom to reflect the world of the student (Freire and Macedo, 1987). Several meta-analyses show positive outcomes for student achievement when educators do (Au and Kawakami, 1994; Scribner, 2001; Padron et al, 2002). 
The use of culturally diverse content is one significant component of culturally relevant pedagogy. As Bishop characterized (1990), culturally diverse texts have the potential to act as "mirrors" for students, reflecting back and validating a student's identity, rather than only acting as "windows" to the outside world. Such texts can be referred to as culturally relevant literature, the focus of this research. In spite of work completed for the past 30 years involving culturally relevant pedagogy, current research is lacking that explicitly addresses the use and impacts of culturally relevant literature. Although the use of culturally relevant literature could be a promising introduction for teachers and students into culturally relevant pedagogy, research has yet to show educators how to complete such a process, nor thoroughly quantified the impacts of doing so.

One challenge in understanding culturally relevant literature is the difficulty of finding a clear definition for it. To many, the label of culturally relevant literature may appear to be the same as multicultural literature, which it is not, as Freeman and Freeman (2004) point out. At its core, multicultural literature promotes the visibility and exposure of multiple cultures or ethnicities to students. Increasing exposure to multiple cultures, however, does not make a text culturally relevant to a reader. It is possible for multicultural literature to overlap and also act as culturally relevant literature, but they do not always do so. So in spite of their similarities, culturally relevant literature needs to be looked in its own right, unattached from the body of research on multicultural literature. This can be done only after establishing a definition of the term.

Unfortunately, scholars have not yet accepted a uniform definition of culturally relevant literature. Instead, two researchers have attempted to describe it by a series of 
qualifiers. In order to assist educators in defining and finding culturally relevant texts, Ouimet (2011) developed an extensive line of questioning, whereas Freeman (as cited in Freeman, Freeman \& Freeman, 2003) developed an eight-point rubric. Freeman's rubric allows assessment of literature for factors of culturally relevancy after reading texts, and educators are encouraged to use it with students. Beyond this, educators may be at a loss for what qualifies as culturally relevant literature, and how to apply it to a specific set of students.

An additional complicating factor is that educators teaching in culturally diverse classrooms are unlikely to be able to decide if a text will or will not be culturally relevant for students in a classroom. Simply put, without knowing how students identify with their cultures, teachers cannot determine what is culturally relevant for them. Even with that knowledge, students remain the experts of their lives, and are most capable of identifying what connects to their culture(s). For example, one study looking at teacher selection of culturally relevant literature for elementary students found disparity between teachers' perceptions of culturally significant books and students' ratings: students rated the teacher-selected books $77 \%$ culturally relevant, versus $96 \%$ rated by teachers (Rodriguez, 2009). Educators concerned with making their classroom more relevant, then, might probe students on what literature they consider to be culturally relevant. These student recommendations could then be incorporated into the curriculum. Unfortunately, no resources in current literature provide guidance on how to go about doing so.

\section{Theoretical Framework}

This explorative study design was informed by critical theory. This theory attempts to explain the replication of inequality, and has been informed by feminism and 
critical race theory, among others, since the 1930's. Scholars such as Paulo Freire and Henry Giroux further developed critical theory into critical pedagogy and literacy, with the intent of helping, "members of marginalized populations learn literacy and civic engagement skills that will allow them to more effectively navigate, resist, and ultimately transform institutions of power." (Morrell, 2009, p. 98) which reflects section of this study. Given that this study focuses on the relationships between culture, literacy, and learning, it is necessary to see literacy Siegel and Fernandez describe, a "social and political practice rather than a set of neutral, psychological skills" (2000, p. 148). Similarly, because this study is situated in critical literacy, it also attempts to "move students toward active position-takings with texts to critique and reconstruct the social fields in which they live and work," as Luke explains (2000, p. 453), shifting from passive recipients of curriculum to active constructors of it.

\section{Statement of the Problem}

With few resources in existence that describe how to identify culturally relevant literature, the problem of this study was determining how to create a process secondary students and teachers could take to identify and select culturally relevant texts. Secondly, this study investigated how the implementation of student-selected culturally relevant literature impacted student engagement, achievement, and interest in culturally relevant texts.

\section{Research Questions}

This action research consisted of three major phases. Phase one involved assessing cultures and representation in curriculum. For phase two, a process to select and read texts representing students' major culture(s) was explored, and then a unit 
centered on culturally relevant texts chosen by students was implemented. Phase three assessed the impact of the unit. For each phase, the following questions were explored: Phase I: Assessing Cultures \& Curriculum Representation

What do students identify as their significant cultures?

Do students evaluate and factor in culturally relevant indicators when selecting books to read? If yes, how do students evaluate literature for cultural relevancy?

What cultures are absent or underrepresented in existing classroom literature?

\section{Phase II: Selection \& Implementation}

What process can students undertake to assess and select literature for cultural relevancy?

\section{Phase III: Assessment}

How might the implementation of culturally relevant novels impact engagement, achievement, and interest in culturally relevant texts for middle school students?

\section{Limitations}

This study was limited by factors that commonly constrain literacy classrooms. Student exploration of available literature and subsequent choices was significantly restricted by local access of materials, available funds for purchasing materials, and the content approval process of the school district. These factors may have influenced the data by reducing cultural relevancy of a selected novel for individual students.

\section{Delimitations}

Some logistical constraints were put into place for this classroom-based research. Rather than have each student select a book that they found to be highly culturally relevant and read it independently, small groups of students were formed around a 
common culturally relevant book. This decision was made to provide cooperative learning opportunities, assist time management in the classroom, and speed up funding approval and content approval times. This decision, however, may have reduced the extent that a book was culturally relevant to individual students. 


\section{CHAPTER TWO: LITERATURE REVIEW}

\section{Determining Cultural Relevancy in Literature}

Only a few methods exist to identify culturally relevant materials, with the most noteworthy being developed by Freeman (as cited in Freeman, Freeman \& Freeman, 2003). The Cultural Relevance Rubric assesses indicators of culturally relevant literature using questions such as, "Does the character talk like I do?" and, "Have I had an experience like the one described in the story?" Indicators used by Freeman include similar setting, time period, likeness to family, age, and gender of main character, language used, and related experiences of reader. These indicators are based off of Goodman's work (1982), which identified life experiences that factored into relevancy; she found that, "the degree of relevance to the readers aids in predictability" of the text (p. 302), an essential element in comprehension. It's important to note, as Freeman does, that cultural relevancy expands beyond race or ethnicity to a variety of other domains; in isolation, one factor such as race does not determine relevancy. The inclusion of a Spanish speaking character, or Mexican geography, for example, is not automatically culturally relevant. Instead, Freeman points out that culturally relevant texts depend on several points of commonality between the reader and the text.

Rudine Sims's critical classification of multicultural literature (1982) is also useful when identifying texts for cultural relevancy. The first category involves "melting pot" texts, which have the appearance of including perspectives from people of color, but avoid depicting sociocultural distinctions, and portray people of color as experiencing the 
world that many white middle class Americans do (Bishop, 2012). These "colorblind" or culturally neutral texts also ignore racial tensions, and are generally written by white authors. Conversely, "culturally conscious" texts have major characters of color and show authentic cultural experiences of them. They are also most frequently written by authors coming from the same cultural background. For the purposes of this study, the second category of texts would likely produce significant cultural connections for students. Conversely, the first kind of book would initially seem relevant, but later disappoint as the lack of cultural connections surfaced. Students or teachers seeking out culturally relevant literature could be easily mislead by "melting pot" texts if only looking at character race, rather than numerous factors.

Ouimet (2011) designed a line of questioning for educators to employ when selecting culturally relevant texts, which also builds off of Bishop's categories. A series of questions qualify texts under three categories: authenticity, realism, and culturally conscious ideology. Many of the questions in Ouimet's work overlap with Freeman's rubric, but Ouimet's work is a lengthier document with language intended for educators rather than students.

In addition to the methods of qualifying texts as relevant, Ladson-Billings (2014) wants to reimagine culturally relevant pedagogy to go beyond static notions of culture, such as race, and embrace a wider scope of what is considered culture, such as "youth" culture. In this sense, culturally relevant literature has the opportunity to serve marginalized students and mainstream students whose subcultures are underrepresented. Conceptualizing culture in such a way may assist mainstream students, who already have 
their static culture represented in literature, to acknowledge other relevant connections and read materials reflecting such.

The terminology and processes each of the authors aforementioned are valuable in categorizing texts for use in this study. In determining what constitutes culturally relevant literature, Freeman (as cited in Freeman, Freeman \& Freeman, 2003) and Ouimet (2011) have similar methods of questioning which successfully ascertain the cultural relevancy of a text. Both also unfortunately necessitate either the reading of a text or significant knowledge of a text in order to complete the assessment thoroughly. Additionally, utilizing Sims Bishop's categories $(1982,2012)$ helps refine what should be considered appropriately authentic choices for texts. Lastly, Ladson-Billings' (2014) work opens up what could fit as significant culture markers.

\section{How Students Use Cultural Relevancy with Texts}

A number of studies acknowledge the complexity of understanding how students use cultural relevancy as they read, and make relevant connections as they read. Sciurba's (2014) case study investigated how two Black adolescent male students connect to texts, which aligned with Bishop's (1990) windows and mirrors analogy. One of the students preferred texts acting as mirrors, while the other preferred texts acting as windows. Yet both students connected and wanted to connect to the two types of texts. Likewise, great variance existed in how the two readers found relevance within texts: "At times relevance involved seeing themselves, and at times it involved extracting meanings they could apply to themselves or lessons they considered 'important"' (p. 314). Indeed, the results of this study reveal how race and gender establishes relevancy for some texts, and yet for others, those factors diminish in relation to other elements such as theme. Sciurba 
cautions against assuming that students will only choose mirrors, as it "does not sufficiently honor the complexities of racial/ethnic or gender identities" (p. 309). She suggests, as does Sleeter (2008), to incorporate choice into the curriculum so that students have the opportunity to select literature functioning as mirrors and as windows.

Brooks (2006) analyzed how urban African American students responded to common features found in award-winning African American children's literature identified as culturally conscious (Sims, 1982). She found that students used their experiences and cultural knowledge to develop "a wide range of literary understandings, such as characterization, metaphor, plot patterns, theme, conflict, and author's intention" (p. 390) for those texts. Even though students came from common backgrounds, there was also a "multiplicitous nature" (p. 390) to how students responded to these features, emphasizing the need to acknowledge cultural complexity. The study thus shows the many ways in which culture aids students in constructing an understanding of a novel.

While studies show students are utilizing cultural relevancy, it is unclear precisely how or when. Similarly, the challenge remains for finding how they utilize this for selecting texts. In working with African American fifth grade students, Gray (2009) attempted to identify what characteristics students used to select African American literature. The vast majority of her data, however, asked students to rank a book after they read a text. Without seeing the data that offers insight into students' pre-reading explanations of interest, rather than just post-reading explanation, the characteristics used to select said literature cannot be determined. Yet the data remains useful in showing what features students cared about as they read. The most important qualities a book could have were connection felt or anticipated towards the main character(s), genre, and 
an appealing book cover. Other notable pre-reading determiners include summary preview on the book and humor. It's important to note than only three percent of responses indicted that African American history was a factor for reading a book. So while "students do notice the ethnicity of the characters in books, and it does play a role in their selection, particularly for realistic fiction", these students did not feel the same way about historical texts (p. 479). Gray notes a disconnect between the availability of texts offered to students (biographical, historical, folk tales), what teachers rank as important criteria for texts (similar to the students) and what the data showed students want to read (realistic fiction.)

\section{Impacts on Engagement, Personal Connections, and Critical Thinking}

Numerous scholars have established a relationship between internal motivation and positive reading outcomes (Schiefele, Schaffner, Möller, \& Wigfield 2012). Similarly, there is a significant overlap between what actions create motivated readers and that of engaged readers. In their study of student motivation and learning, Hulleman and Harackiewicz (2009) found that a student's ability to relate to content is tied to engagement. Likewise, there is a strong connection between engaged reading and reading achievement. Guthrie (2001) found that the amount of engaged reading for $4^{\text {th }}$ grade students predicted reading achievement. This was the case even when statistically controlling for variables such as SES, background knowledge, and reading motivation. Engagement, then, can serve as a predictor for achievement - a key consideration for working with underserved or oppressed populations. Nearly all of the studies reviewed within this section reported an increase of engagement for adolescent and elementary students while reading culturally relevant literature. 
In Rodriguez' (2009) study, pre-service teachers taught elementary students using culturally relevant texts and documented the effects on both sets of participants. Preservice teachers observed engaged readers making connections and accurately predicting while reading. Participants noted that ELL students felt teachers cared about them when using such texts. Five themes emerged from participants' reflections about the outcomes of using culturally relevant literature: connections, engagement, communication, empowerment, and motivation. These themes are echoed in the majority of the studies in this literature review.

Feger (2006), for example, found a strong relationship between the use of culturally relevant books and students' desire to read while ninth and tenth grade ELL students studied culturally relevant literature. "The more I had incorporated culturally relevant literature and non-fiction into the curriculum, the more my students' engagement in reading had increased" (p. 18). This is for a classroom containing a majority of Spanish-speaking ELL students. While using culturally relevant literature such as The Circuit: Stories from the Life of a Migrant Child (Jiménez, 1997) and My Name is Jorge on Both Sides of the River (Medina, 1999), Feger saw an increase of engagement, critical thinking, and making of personal connections. Rodriguez (2009), reflecting on Feger's study, asserts that students have better opportunities to explore their own identities when reading culturally relevant texts.

In his critical participatory action research with high school students of color, Camangian (2015) utilized relevant texts and developed curriculum to arouse, agitate, and inspire. His analysis, echoes Feger's (2006), stating that, "The more relevant the curriculum was made to respond the students and communities' humanizing needs, the 
more students were interested in practicing traditional academic literacies.” (p. 442.)

Incredibly, all students in this study passed the state test that year, compared to a schoolwide average of $42 \%$. This data is incomplete, however, without factoring in success rates of those same students in prior years, which is not included.

In working with junior high students originating from the Dominican Republic, Herrero (2006) also saw enrichment of academic skills when students interacted with culturally relevant materials. When discussing fables taken from texts, student discussion of the literature was limited to academic concepts. Yet when discussing student-obtained cultural narratives, students accessed personal knowledge, community literary concepts, and academic concepts of literature to analyze form, content, and language. Having the opportunity to draw from both community and academic concepts while working with their cultural narratives consequently deepened students' critical analysis of the literature and narrative form. Because of this, Herrero concludes that the, "Use of cultural literature and practices fostered pride, participation, commitment and success in completing the tasks" (p. 237).

Frequently cited, Jimenez' (1997) work with Hispanic students from ELL and Special Education classrooms explored how to meet students' multiple needs without stigmatizing them in the process. Methods for the seventh grade students included the use of culturally relevant texts and think alouds. Through qualitative analysis, Jimenez concluded that culturally familiar texts best met students' literacy needs. By linking to their own background, students were able to ask questions and make inferences. In addition, results showed students strengthening their metacognitive awareness during reading, which in turn increased reading comprehension. Jimenez acknowledged the 
limitations of this research due to the small sample size, yet no duplication of this study was found for this review.

In addition to engagement, many of the aforementioned studies remarked on students accessing background knowledge and making predictions. Pérez (as cited in Ebe, 2010) concludes, "the background knowledge and experiences that students bring to literacy tasks are perhaps the most important elements that influence children's ability to read with high levels of comprehension and write coherent and cohesive texts" (p. 195). Culturally relevant literature increases the likelihood of background knowledge being accessed during literacy tasks.

Beyond the impacts on engagement and ability to make connections, many of these studies show the use of culturally relevant texts assisting students in validating their experiences and finding their voice. Robbins (2001) explored using culturally relevant literature as a vehicle for identifying "invisible dynamics" of power and race existing in a multiracial, predominantly (70\%) Hispanic classroom. After conducting inquiry-based discussions based on short pieces of literature from Medina (1999) and Jimenez (1997), Robbins reported that seventh and eighth grade students were able to realize and identify oppressive forces that impacted their lives. This provided opportunity for students to "cross the cultural bridge with the other", perhaps for the first time (p. 23). Robbins saw students' self-identification began to shift as a result of these activities. Robbins found that these texts and strategies brought about an increase of empathy, hope, an ability to problem-solve in relation to racial tensions, and form positive identities.

In juxtaposition with Robbins, Dressel (2005) analyzed the effects of teaching a multicultural literature unit to mainstream, predominantly white $(93 \%)$ eighth grade 
students. The study showed that over $70 \%$ did not increase their awareness of underlying cultural assumptions nor cultural pressures placed on the characters. They also rejected or reshaped the events of texts when they were in conflict with their own experiences, and at the end of the unit, were more likely to identify people in nondominant cultures as "others". These results have significant implications for educators in classrooms where multiple cultures may be addressed within a unit. It calls attention to the importance of teacher as facilitator connecting students from diverse backgrounds through literature that is a mirror to some and a window to others to ensure that a literature study does not increase an identification of "otherness".

Whether a part of the minority or majority in the classroom, a student's success can be influenced by a lack of culturally relevant teaching. In a case study of one disengaged Hispanic adolescent, Ma'ayan (2010) observed that the student was failing academically, had repeated fourth grade, and was frequently silent in class. Yet she found that culturally responsive teaching tapped into her existing knowledge and strengths. Literature discussion circles and culturally relevant literature, such as The House of Mango Street (Cisneros, 1989) brought out increased engagement for this student. Ma'ayan recommended culturally relevant teaching strategies to reach students like these, such as giving the student increased opportunity to produce materials involving one's culture, and permitting access to materials that some may not consider "age-appropriate", but nonetheless reflect a student's life experiences. Gibson's work with African American girls (2010) parallels the conclusions of this study and supports engaging adolescent girls' under-utilized literacy strengths.

This group of studies indicates that the use of culturally relevant literature 
improves engagement, increases personal connections to texts, and metacognitive awareness while reading. Some of the results suggest improved academic achievement, and one indicated a negative impact on cultural assumptions. A common shortcoming in this set of studies is that they often lack specific, quantifiable data beyond teacher observation, which thus reduces the reliability of the results.

\section{Reading Comprehension With Culturally Relevant Texts}

Although the analysis conducted for this study does not specifically measure comprehension rates, the underlying purpose of using culturally relevant literature is to improve engagement and comprehension. Accordingly, the following examines how comprehension has improved with the use of culturally relevant materials. There are two significant contributors to the field that have analyzed the effects of relevant texts on comprehension. Garcia (1991) analyzed Hispanic student reading test performance, which showed that background knowledge of $5^{\text {th }}$ and $6^{\text {th }}$ grade students significantly affected reading test performance. When controlling for background knowledge in the statistical analysis, differences in performance of Hispanic students to Caucasian students disappeared. The study also found that Hispanic students performed lower for questions involving implicit information, even when controlling for prior knowledge. The authors suggest this could be due to differences in instruction, especially if Hispanic students were placed into lower reading groups, where decoding might be emphasized over analyzing implicit information. The results of this study support the use of culturally relevant literature in order to provide students the opportunity to access and utilize their background knowledge when reading. 
Ebe's research repeatedly confirms that culturally relevant reading passages positively influence comprehension assessment. Three studies, each with different age groups, explored comprehension, recall, and miscue analysis. She first addressed this with Hispanic middle and high school students (as cited in Freeman, Freeman \& Freeman, 2003). After using an excerpt from Family Pictures: Cuadros de Familia (Garza, 1995), she found students made many personal connections. Comparing miscue analyses and story retellings from this story to a non-culturally relevant story, students had a higher level of comprehension than the latter text. Ebe repeated this study at the third grade level with nine students. When students read the culturally relevant passage, they were more proficient in reading it. Even though both passages were at the same reading level and within the reader's instructional reading zone, "the readers made more high quality miscues that made sense and were grammatically correct when reading the story to which they related" (Ebe, 2010, p. 208). This study was once again completed with a small number of $7^{\text {th }}$ grade students, which garnered very similar results (Ebe, 2012). Kelley et al. (2015) corroborated Ebe's work in a similar study.

In an exploratory study involving personal connections and comprehension recall, Fogarty et al. (2017) found explicitly asking students to make connections to a narrative text, such as telling students to make personal connections prior to reading and afterwards asking, "How does this story relate to your life?" increased comprehension of a short story for both proficient and struggling readers. The authors noted that struggling readers might need direct prompting in order to perform this task while reading. Without specifically addressing the cultural component of relevant literature, this study reinforces that explicitly asking students to identify relevancy improves comprehension. These 
results also support the idea that culturally relevant literature improves comprehension by increasing a reader's exposure to relevant topics and thus their frequency of making connections.

As noted in this selection of research, the use of culturally relevant literature in classrooms improves or reveals higher comprehension levels settings, as does asking students to make relevant connections from the text to their lives while they read. 


\section{CHAPTER THREE: METHODOLOGY}

\section{Context \& Participants}

This study was conducted over a spring semester with an eight week period of intervention. The study took place in a suburban 6-8 middle school in the Western United States, serving approximately 1,000 students with a $36 \%$ minority population, predominantly Hispanic. It qualified as a Title 1 school with $60 \%$ of students qualifying for the federal free/reduced lunch program. The sample of students derived from two sections of standard seventh grade English language arts classes. Of approximately 55 students, 22 consented to participating in the study. One student changed classrooms midunit. Survey data revealed that the sample matched school diversity, with $52 \%$ White/Caucasian, 33\% Hispanic, and 5\% Black/African American students. Upon review of survey data of racial make-up, no significant differences occurred between the participants and the accessible population.

\section{Phase I}

This study had three major phases of inquiry. In phase I, students explored and identified the significant cultures they belong to. A baseline was taken in the form of a digital survey, which asked participants to identify demographics, genre interest, and identify to what extent cultural indicators influence how they select books (see appendix A.) One portion of the survey pulled from Roberts \& Phinney's Multigroup Ethnic Identity Measure (1999), in order to identify cultural identity awareness and belonging. Once completed, students explored defining culture, with the assistance of Hall's cultural 
iceberg concept (1976). Afterwards, they identified what they considered their own significant cultures, employing Short's (2009) cultural x-ray graphic organizer. Following identification of their own cultures, students critiqued how cultures were represented in the current literature curriculum. Since staff at the school predominantly used novel sets, students only focused their analysis on novel sets instead of other resources.

\section{Phase II}

In phase II of the study, the teacher-researcher and students explored how to assess and select novels that authentically represented one or more of the students' significant and potentially underrepresented cultures. This was to be accomplished in part by seeking out novels awarded for excellence in cultural representation. Students engaged in book previews and later were placed into small groups of two to six students for literature circles. Students read independently and with partners, completing weekly write-ups for literature circle meetings run by students. As they worked through the texts, elements of critical literacy, such as critiquing power and perspectives in the novel, were touched upon.

\section{Phase III}

As students finished their literature circles and novels, students were given a choice of projects and prompts to respond to, including a book critique and a persuasive letter on the use of culturally relevant literature in the curriculum.

In addition to final surveys (see appendix B), reflections and field notes were collected by the teacher-researcher. Student work of weekly write-ups, audio recording of literature circle discussions, and final written projects evaluating culturally relevant 
literature and the use of such were collected and assessed. Student grades were also analyzed for shifts in work completion rates, as an indicator of engagement and achievement. 


\section{CHAPTER FOUR: RESULTS}

\section{Introduction}

This chapter describes the findings of this study on creating a process secondary students and teachers can follow to identify, select and employ culturally relevant texts. This chapter is divided by research questions and the subsequent data collected.

\section{Phase I Findings}

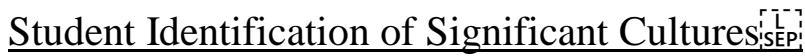

Understanding the manner in which students perceived culture and identified their own major cultural groups was a pivotal step in establishing the context of the work to be done. Through the use of the cultural iceberg (Hall, 1976) and discussion of what makes up culture, students showed that they understood how to define culture. Yet in application to their own lives, a portion of students had difficulty identifying and labeling themselves. When initially asked to identify their significant culture, multiple Caucasian students initially remarked that they "Had no culture." Initial survey data also indicated student uncertainty regarding their background, with nearly $20 \%$ of students not feeling they had a clear sense of their ethnic background and what it meant for them. In spite of that, $100 \%$ of students agreed or strongly agreed that they felt good about their cultural or ethnic background. So even though a portion didn't understand what culture meant for them, they nonetheless felt positively about their background. Given the transformation that occurs during adolescence, it comes as no surprise that a portion of these young adolescent students were unsure of such and had not solidified their cultural identity. 
In spite of some uncertainty regarding cultural identity, students were able to quickly construct a greater cultural awareness. One such conversation between two students is an example of such:

Steven: "Is there such as thing as American culture?"

Katie: "Oh yes!"

Steven: "Oh. Then I'm a part of American culture."

Katie: "Yes!"

In order to facilitate student understanding of the multifaceted nature of culture, less rigid elements of culture, such as language, gender, class, generation, and religion were discussed. In doing so, students and teacher-researcher followed Ladson-Billings (2014) call to include more fluid concepts of culture. Later on, these concepts would appear on students' cultural x-rays and written descriptions of their most significant culture(s).

Ultimately, students described their significant cultures in different and more substantial ways than how they identified their ethnic/racial background. While pre-unit surveys indicated ethnic diversity at 52\% White/Caucasian, 33\% Hispanic, and 5\% Black/African American students, written descriptions of significant cultures included 56\% American, 50\% Christian, 31\% Hispanic, 5\% African American, and with additional descriptors such as middle class and Millennial generation. In comparing this data, some overlap exists between ethnic/racial background and identification of significant culture, but it is clear that ethnic background does not always equate to student-identified significant culture(s). Instead, a few interesting points emerge. First, zero Caucasian students labeled their significant culture as white or Caucasian culture, either not 
mentioning ethnicity at all or subsuming it under the label American, whereas all Hispanic and Black students included their racial/ethnic background as a significant culture. Secondly, Christian culture emerged as a strong signifier for students.

Additionally, half of students included more than one significant culture in their response. In conclusion, although students showed an understanding of culture, some struggled initially to identify what cultures they were a part of. Students were able, however, to learn further aspects of culture and apply them to their lives. Students did not automatically identify ethnic background as a significant culture, which further reinforces the need for student voice when selecting relevant texts.

\section{Do Students Assess Books for Cultural Relevancy?}

Survey results show that, pre-unit, students did not place importance on gender, time period, or race/ethnicity of main character or book. As seen in table 1.1, only $13 \%$ of students pre-unit agreed that a main character having the same gender as them was important when reading a novel, and $11 \%$ agreed that they would prefer to read such a text. For time period, $13.8 \%$ agreed or strongly agreed that a book set in current times was important, and $26 \%$ said they preferred it. For a book to share the race/ethnicity of the reader, $13.7 \%$ said it was important, and $13.7 \%$ said they would rather read such a text. In asking students pre-unit to rank the reasons why they select a text, students reported that the top three reasons for selecting a text were other/non-specified reasons, recommendation, and genre. The most frequently cited reasons of least important factors were "having characters or setting similar to me", and "looks like an easy read". Since students were not placing importance on these factors nor ranking having a similar 
character or setting as important factors when selecting a text, it can be concluded that they were not consciously assessing texts for cultural relevancy.

Students' preferences of culturally relevant factors in novels changed slightly post-unit. In regards to gender, $21 \%$ agreed that a main character having the same gender was important when reading a novel, and $21 \%$ agreed that they would prefer to read such a text. When the results are broken down by gender, male students were more likely to shift to agreeing post-unit that they would prefer a protagonist with the same gender, whereas no female students indicated so pre- or post-unit. For time period, $17.7 \%$ agreed or strongly agreed that a book set in current times was important, and 13\% said they preferred it. For a book to share the race/ethnicity of the reader, 17\% said it was important, and 23\% said they would rather read such a text. When these results were broken down by race, no significant differences existed between the way minority students and Caucasian students shifted views pre-unit to post-unit. In review student ranking data, "having a similar character or setting" positively shifted, so that students were more likely to rank it in the top half of importance than the bottom half. Survey data thus suggests that students were not selecting texts for culturally relevant factors, and the unit of study slightly shifted their preferences for said factors. 
Table 1.1 Cultural Elements Pre-Post Comparison

\begin{tabular}{|l|l|l|l|}
\hline \multicolumn{2}{|l|}{ Cultural Elements } & Pre-Unit & Post-Unit \\
\hline \multirow{2}{*}{ Gender } & Important & $13 \%$ & $21 \%$ \\
\cline { 2 - 4 } & Prefer & $11 \%$ & $21 \%$ \\
\hline \multirow{2}{*}{ Time Period } & Important & $13.8 \%$ & 17.7 \\
\cline { 2 - 4 } & Prefer & $26 \%$ & $13 \%$ \\
\hline \multirow{2}{*}{ Race/Ethnicity } & Important & $13.7 \%$ & $17 \%$ \\
\cline { 2 - 4 } & Prefer & $13.7 \%$ & $23 \%$ \\
\hline
\end{tabular}

\section{Cultural Representation in Existing Curriculum}

Although I was aware of the lack of diversity in the curriculum, I wanted to engage students in the process of analyzing the curriculum, to see how they viewed the options offered to them, and to see if they came to similar conclusions about a need for increase in diverse, relevant texts in the curriculum. The process used to critique the curriculum became the first experiment in assessing culturally relevant novels as a class, and is discussed in detail later on in this chapter. Using a critique chart, of which a completed sample is seen in figure 1, students conducted small group book previews to gather cultural information about the novels and summarize the results.

After completing the activity, both classes determined that novels available as class sets predominantly featured white, male characters, and/or were frequently set during WWII. When prompted to identify which of their cultures were missing, students most frequently noted that female protagonists, Hispanic protagonists, and religion were 
underrepresented or missing. Shana, who identified her significant cultures as American, Christian, and African American, wrote that, "Females and other races that are a part of my cultures" were missing from the curriculum. Javier noted simply, "There should be more culture."

This classroom activity thus began building awareness for students on the lack of diversity found in curriculum. It naturally led to the question: Who else should be represented? and asked students to question whether their cultures should be represented too. In doing so, it allowed students to become co-collaborators in the research, and established a need for finding more diverse, culturally relevant texts. 


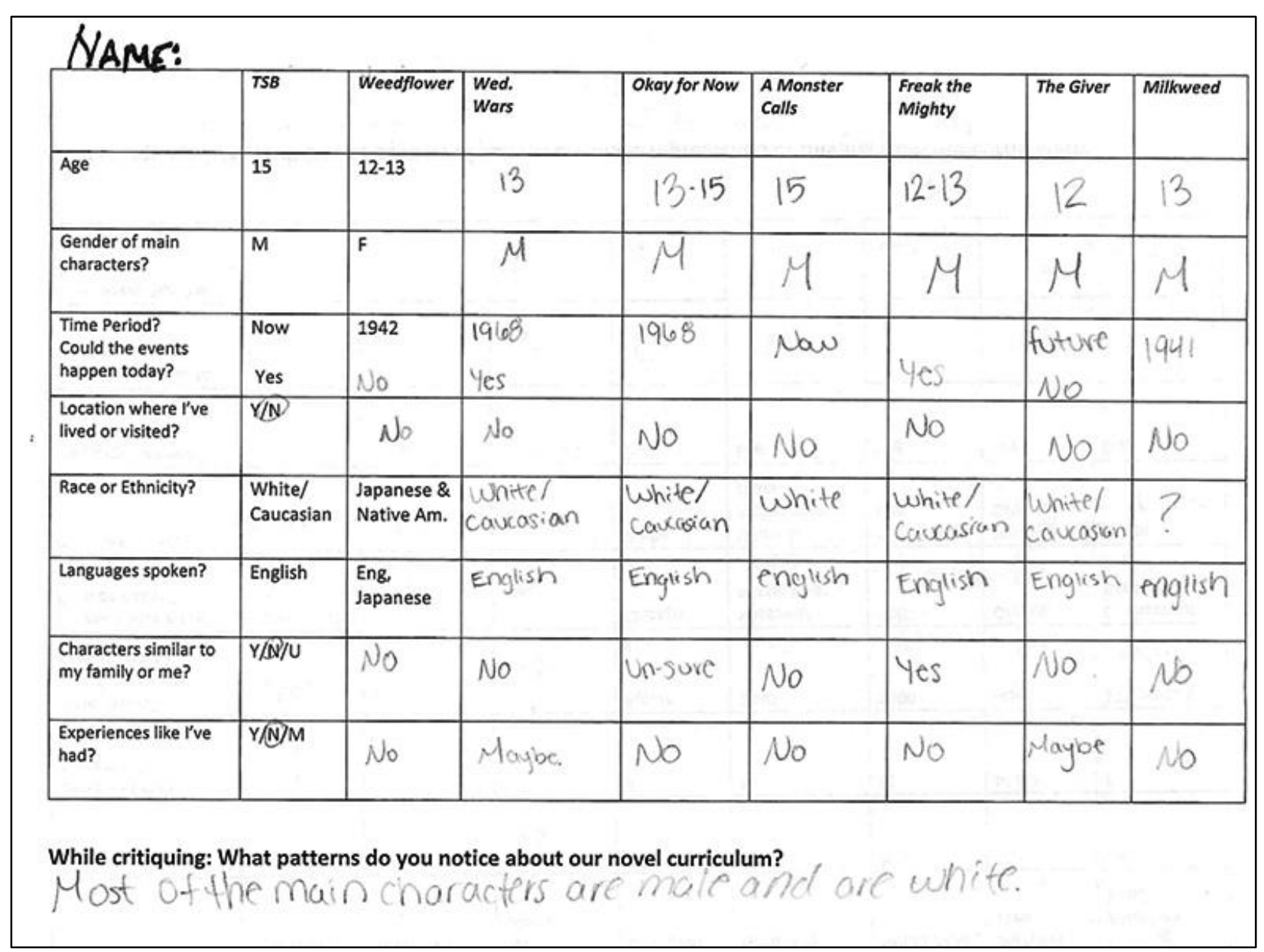

Figure 1: Example of a Completed Curriculum Critique

Phase II Findings

SEPPThe Process to Assess and Select Culturally Relevant Literature

Creating a process for students to assess cultural relevancy in literature first began with the development of a curriculum critique. To do so, Freeman's (as cited in Freeman, Freeman \& Freeman, 2003) rubric was simplified into yes/no questions, and formatted into a chart to analyze cultural elements found in existing novel sets. The two-page document (see appendix C) listed every novel on the seventh grade novel list. Some book data was filled in on the chart in order to reduce the number of books students would need to review. The activity took place during one 50-minute class period, where small groups rotated around stations of books. This process highly engrossed students, 
engaging their inferring skills and generating discussion about how someone in the group was able to determine the protagonist or time period. Students were asked to determine as many factors as they could for every book, with the knowledge that not all would be found in the 5-minute time frame. In addition to practicing inference, a second unintended benefit from this preview was that it generated interest in a number of books students would read later in the year.

The structure of the curriculum critique was replicated to help students assess and select culturally relevant novels for our literature unit. The same simplified cultural relevance rubric was used, and one element was added; students were asked to rate 1-4 how potentially relevant the novel they thought the book would be for them. Once completed, students were to list their top three choices on the cultural relevance form (see appendix D) and explain their reasoning for their selections.

\section{$\underline{\text { Book Preview }}$}

Conducting a book preview required gathering a large number of novels that could be culturally relevant for a diverse set of students, which was a time-consuming and challenging endeavor. Since any book already within the district was approved, and thus did not require a lengthy approval process, district libraries were scoured. Although new books could have been previewed and purchased, district approval would have required more time than we had before beginning the literature unit. Given the high percentage of Hispanic students, libraries were crosschecked for award winning books from the Pura Belpre Award, Tomás Rivera Mexican American Children’s Book Award, and the Américas Award. Less than a dozen were available and age-appropriate. At that point, with the help of teacher assistants and library aids, every book potentially featuring 
women or minorities was pulled from the school library, and then screened by the teacher-researcher for culturally conscious, authentic texts (Ouimet, 2011). Approximately 80 books were gathered in this process for student previews.

For the book preview activity, students gathered around the stacks of curated books, loosely organized by significant cultures. Students were asked to preview a book for five minutes. During this time, they were encouraged to move between tables, discuss the books with those around them, and assess how potentially relevant they thought the book would be for them. In this process, I did not hear any conversation about choosing a book because it was short. At the end of the activity, students ranked their top three choices for the reading unit. During this time, a few students in each class struggled to find books that they connected with; a group of Caucasian girls were particularly dissatisfied with their options. Some boys completed the preview too quickly (less than three minutes) and others exhibited group behavior, such as moving tables as a whole or discussing one book between 3-4 students at a time.

After completing the book preview, students gave feedback on the process. Opposing views existed on the amount of time; one student said it took too long, whereas another complained that they did not have enough time at five minutes per book. One student suggested the process would be better if someone were able to talk about the book to the students. Erick thought some questions should be removed from the list because they were too difficult to determine; those were questions asking about similarity to life, family, and, occasionally, location. Sofia liked the process, noting the cultural significance of the books offered to her, stating that it was easy to see yourself in the 
situation and, "Wonder what you'd do." Unsurprisingly, three students also commented on wanting more diversity of texts and diversity of authors.

By comparing student data written on the cultural relevance preview charts to that of the selection forms, factors of how students made their book choices can be seen. As expected, the majority of participants described cultural relevancy when explaining their selections. Kizzie, for example, cited which relevant elements she saw in each of her top choices, describing her top choice with, "My life is almost the same." General interest in a book, described by comments such as "It looks like a good book" or, "It looks interesting" was the second-most cited reason for book selection. For many, there was not an abundance of anticipated highly culturally relevant novels, so when it came time to make a third selection, student explanations describe only one or two relatable factors. Correspondingly, when students selected their third choice, interest was cited just as frequently as relevancy. While over half of participants' top three choices were the highest-ranking books for potential relevancy, a significant portion of students favored a book with a lower rating over one with a higher rating. At least three students chose books knowing they would not be, or anticipating they would not be, relevant. This information is particularly enlightening because it shows that certain factors were more important to students than straight relevancy. Furthermore, it shows that interest was more important than following the goal given to them by the teacher-researcher, which was, "to find a culturally relevant novel." The descriptions of student reasoning suggests that topic interest and engaging opening pages, among others, influenced how students selected their top choices. For example, as a first generation Mexican American, Blanca's top choice was Crossing the Wire (Hobbs, 2007), a book almost exclusively featuring 
male characters emigrating from Mexico. While she rated its potential relevancy a three out of four, she rated her second and third choices higher. Wondering if she missed some information in the book preview, I checked in with her to see if she would rather read one of the novels that featured a young Latina in the United States instead. She maintained her first choice. In the final survey, Blanca cited its relevancy to her because it involved immigration. For Blanca, protagonist gender was not a deciding factor, whereas topic interest was. These results indicate that, although gender and race are significant cultural markers, they do not always predict interest in a text for students. One additional noncultural factor to shape book selection was the opportunity for peer interaction, which was observed through a few students deciding and writing top choices together. This data suggests that, while cultural relevancy may increase reader interest, other competing factors exist that motivate students to want to read some books over others.

In addition to the balance between cultural relevancy and competing student interests, grouping students for the purpose of the literature circles presented its own challenge. During the process, it became clear that a handful of students in each class did not connect with the same books as their peers. Instead of forcing students into groups, those students were given the option to read the novels independently, rather than decrease the relevancy of their reading material. This increased the number of books being read in the classroom to a total of 19 books for the two sections. An unintended benefit of allowing students to read novels independently was that it saved money by decreasing the need to purchase additional copies of novels. 


\section{$\underline{\text { Accuracy of Student Relevancy Predictions }}$}

Accuracy of student prediction for cultural relevancy was analyzed by use of final survey data. Students were asked to describe how they thought the book would relate to them and their culture when they first picked the book, and secondly describe how the book actually related. As seen in figure 2, 26\% of students were not at all or only a little accurate in their predictions, $26 \%$ were somewhat accurate in their predictions, and the remaining $47 \%$ were either accurate or highly accurate in their predictions about the relevancy of the novel. These miscalculations resulted in both relevant and irrelevant novel reading. For example, Cecelia chose the book because it looked not, thinking it would relate, yet afterwards did find some relevancy to her own experiences. Lizbeth, on the other hand, believed it would be relatable, but found that the main character was almost nothing like her life or family. Additionally, the antecedents leading to accurate predictions also varied. Some students, for example, choose books based on interest or genre, accurately predicting that their selection would not be relevant to them. For others, they sought out relevant books and ultimately did find them. 


\section{Accuracy of Student Prediction Vs. Actual Relevancy}

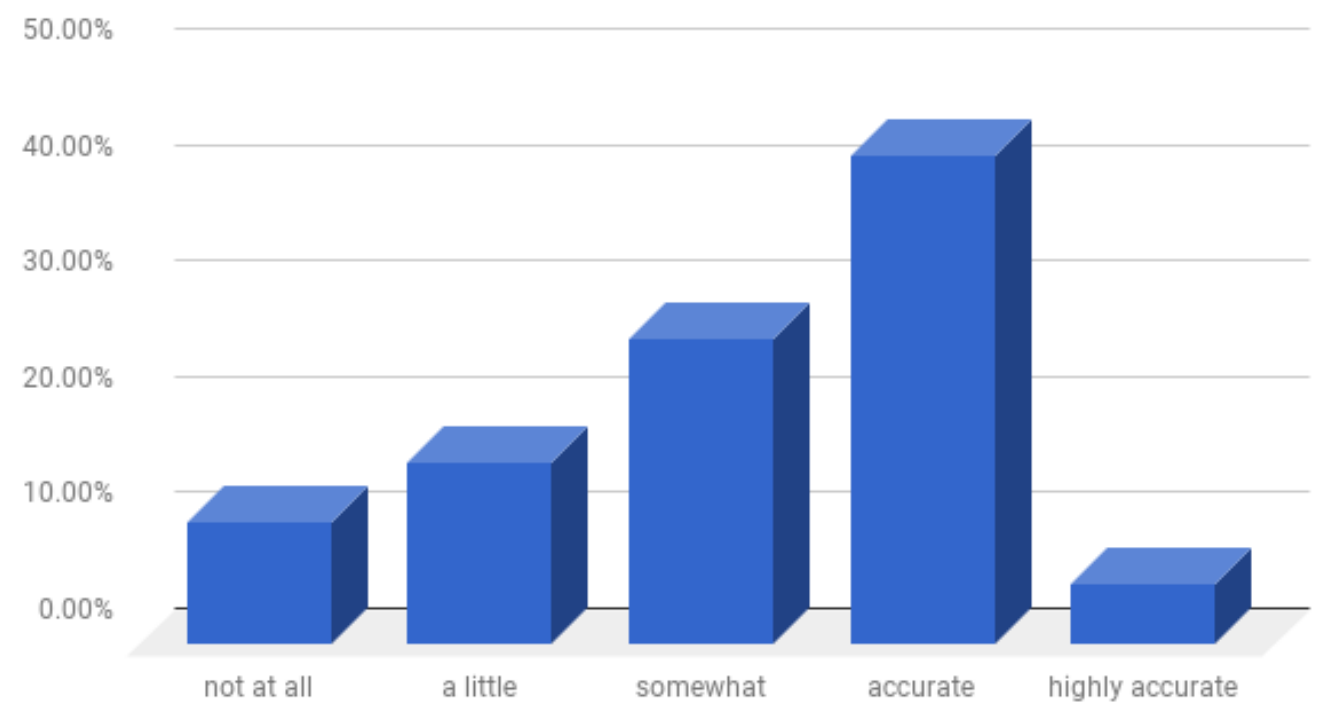

Figure 2: $\quad$ Comparison of Student Prediction Vs. Actual Relevancy

\section{$\underline{\text { Literature Circle Unit }}$}

Once the selection process was complete, a literature circle format was used to structure the reading and discussion of the texts. Organizing it in in this manner brought students and their personal analysis to the forefront of the unit. In the form of a weekly write-up, students visualized, summarized, predicted, connected, and questioned what they were reading. During weekly meetings, students then used their writing to begin discussion and allow it to generate further points of discussion. This method stands in contrasts to tradition whole-class novel units, where students most often respond to teacher-generated topics and teacher-prompted analysis questions. Using literature circles encouraged student agency, allowing students to direct their learning with the novel and emphasize how they interacted with the texts. Using the structure of a literature circle also fit well with managing the large number of novels being read in the class at once. 
In addition to sharing reflections and connections during the meeting, students also engaged in critical discussion analyzing the realism and cultural consciousness of the novels (Ouimet, 2011). Data was gathered at the end of each meeting regarding group critique of these elements. Using Ouimet's questions on realism as critique guidelines, $86 \%$ of students agreed that yes, their novels were realistic. Examples of realism cited from novels included depiction of a poor community, family dynamics, racial bias, and deportation. In discussing whether they thought culture or color of skin mattered to the story, $80 \%$ of students in the first class said yes, while in the second class, $42 \%$ said yes. As a follow-up poll, 9 of 14 students who said "No" in the second class agreed that race was not discussed, mentioned, or "seen". This information suggests that a portion of students in the second class selected colorblind or culturally neutral texts (Sims, 1982), which would have an effective of reducing the opportunity to draw cultural parallels between the novel and students' lives.

\section{Concluding Assessment \& Projects}

As students finished reading their novels, they completed two projects to reflect their understanding and assessment of their novel: one with a writing emphasis, one with a visual/graphic emphasis. For the writing project, most students chose to write a book critique, which discussed the realism, cultural perspectives, and quality of the novel.

\section{$\underline{\text { Student Assessment of Novel Relevancy }}$}

As seen in Figure 3, when students were asked a multiple choice question if they thought their novel was culturally relevant, 50\% of participants responded "Yes" the book was culturally relevant. This mirrors the overall percent from all students, at $46 \%$. An additional $16 \%$ of students were unsure if the book was culturally relevant or not, and 
$33 \%$ of students did not think their novel was culturally relevant. In reviewing these responses, I was surprised seeing that some students reported "No" when I thought the novels would be highly relevant for them. After inquiring about their rationales with a few students, it became clear that at least a small portion of students disqualified a book because of the presence of a noted difference between the protagonist and the student. For example, Javier explained that he marked "No" because the character in Breaking Through (Jiménez, 2001) was in a "Run and hide situation", while Javier and his family were documented immigrants from Mexico. By analyzing student open-ended short responses and comparing them to their multiple-choice responses, a clearer understanding can be seen concerning the extent to which students culturally connected to their novels. In Cecelia's case, she answered, "Yes", agreeing that it was culturally relevant, but only noted one relevant connection between the book and herself: that of middle school life. As a result of this integrated analysis, Cecelia's relevancy was downgraded to "somewhat" relevant to her. Conversely, because Javier noted four points of relevancy on his short response- race, class, religion, and "overcoming challenges", his novel was classified as "relevant". When analyzing relevancy by incorporating both multiple choice and open-ended short responses, $14 \%$ of students found a novel "not at all" relevant, 19\% found novels that were "a little" relevant, 24\% found a "somewhat" relevant novel, 29\% found a relevant novel, and $14 \%$ of students found a highly relevant novel. In both examples, neither Javier nor Cecelia acknowledged gender as a part of their points of connection, in spite of both sharing gender with the protagonist of their novels. Few students did. 
Relevancy According to Multiple Choice Response

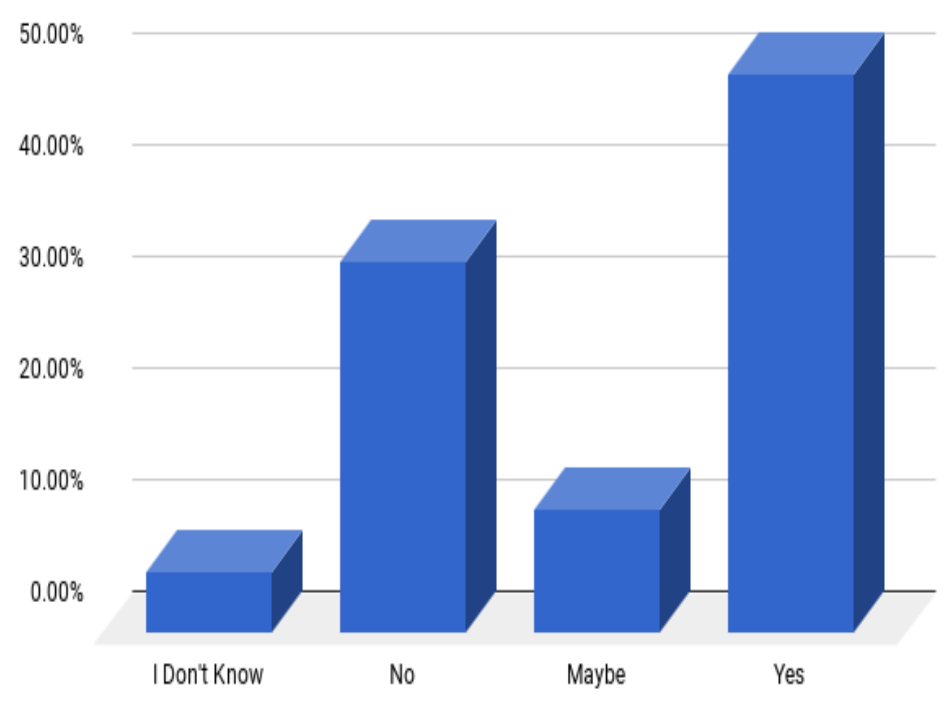

Relevancy According to Short Answer Analysis

$50.00 \%$

$40.00 \%$

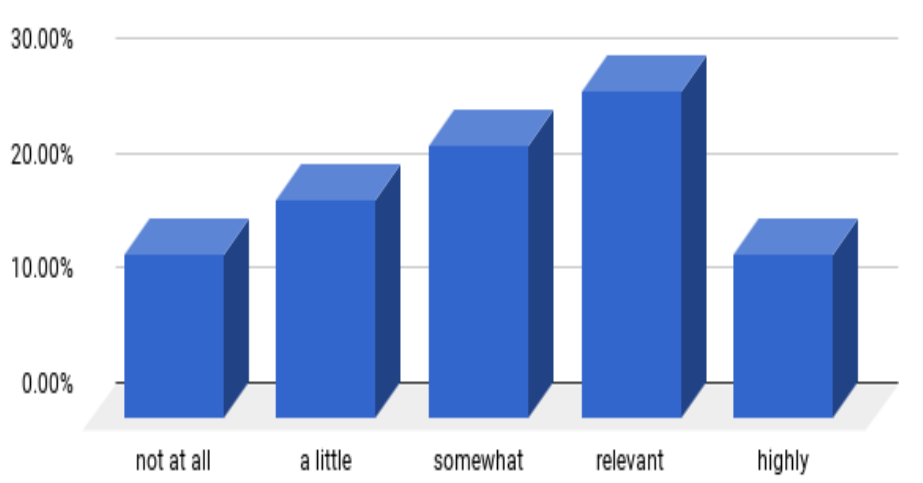

Figure 3: Comparison of Relevancy by Survey Response

Phase III Findings

\section{Culturally Relevant Novel Use Impact on Achievement}

Academic achievement was briefly investigated by comparing turn-in rates from first semester to that of the unit. For the participants, the majority of students had a neutral shift of less than $10 \%$ positive or negative in how often they turned in work. Only one student showed significant decline in work turned in of greater than $20 \%$, whereas 7 of 20 students showed positive growth of turning in work of greater than $10 \%$, with the highest increase being $43 \%$. The majority of learners thus experienced a neutral or slightly positive shift in their completion rates during this unit. These results demonstrate that the literature unit did not negatively impact turn-in rates.

Culturally Relevant Novel Use Impact on Engagement 
In order to evaluate engagement occurring during the literature unit, the following indicators were reviewed: student willingness to participate, displays of motivation, connections to the learning unit, and effort relative to other units. The main points of data collection examined were field notes tracking behavior during reading time and meetings, student write-ups, final projects, and audio of literature circle meetings. During reading time throughout the unit, students exhibited positive behavior, some of which was unique to this unit and otherwise not seen during the school year. In one instance, two of the lowest achieving students in class repeatedly asked me to partner-read during the unit. I was reluctant to allow them, as the noise distracted some students, but they continued to ask me, insisting that it was helping them understand the book and offering to paraphrase their recent reading to prove it. They were predominantly on-task. In another example, after prompting one student to check in with a group member, he relayed that, "He told me to go to page 60 and find out more about Tia's magic," and then did so. Such in-depth interactions were observed again later in their last literature circle meeting, showing how actively engaged these two Latino students were. This is particularly significant given how low achieving the two students were otherwise during the year. In one class, multiple sets of students, without prompting by the teacher, walked to a peer's desk during reading time, pointed out a funny or alarming part of the book, snickering, and returned to their seats. For a certain number of students, the realism presented in the books felt taboo, which increased their engagement in the texts. One student, Charlie, leaned over to my desk to report that there was a swear word in the book. "Yes, sometimes that happens," was my reply. He then turned to his neighbor and told them, "I like this book." Finishing ahead of the class, Katie and her partner asked if they could 
invent their own final project to work on after finishing their novel. While these provide examples as to the high engagement existing in the classroom, this unit was also not a fix-it. Rather, many students who were typically off-task during independent reading time in the year continued needing frequent prompting to return to their work during this unit.

Whereas reading behavior indicates high engagement, behavior during literature circle meetings and corresponding student write-ups show a comparable amount of effort and engagement to past years of literature circles. The effort put in or the quality of work for student write-ups and for final projects was typical to that of other classwork for nearly all participants. Yet as Ma'ayan (2010) discussed, conversations that included nontraditional literacies, such as film, sparked a connection between media students were engaging in at home to their class novels. When reminding my reading group of all Latino boys that they could make connections to other texts like movies, it initiated a conversation that involved each boy in the group comparing and predicting how the novel might end up being like movies they had seen, and making recommendations to me, the teacher, to watch those movies. Creating that space allowed those students to access and connect their world to the word of the classroom.

Whole class conversations involving critical literacy and cultural assessment, such as one involving to what extent culture or skin color mattered in the book, once again brought about high engagement in students, with volunteers providing specific evidence to show their understanding of the topic at hand from their novels.

Final projects from students uncovered students' deep interactions, and reflections on what they read in the unit. Shana employed critical literacy skills when noting, "Every character was Caucasian and was somewhat rich...the main voice that was silenced was 
the poor people." Javier also analyzed the novel thoroughly, citing the novel to show how culture mattered in the novel, and using his own religious background to assess the religious life of the protagonist. Kizzie noted that, "My life or culture hasn't really been represented in any book in this school" other than the novel for this unit, and argued for more books that could echo her experience, so that, "[students] would reflect on a book and on themselves, and maybe even realize more about themselves." Likewise, Lizbeth spoke to the value of student choice, asking for more appealing books and to "give more options" so that students could find something that was appealing to them from the start. Cecelia noted that although, "There was nothing about race", in the novel she read, she was able to connect the fighting in the novel thematically to current events and her own life. Conversely, Rubin noted the realism of Mexicans crossing the border in his book and how, "We don't hear [Mexicans'] voices a lot in real life," showing how he was engaging with the text to make critical, text-to-world connections.

As shown, this literature unit increased engagement during reading time for individual students and text-dependent interaction between students. When reviewing completion rates and quality of written work, data shows that both maintained previous levels of performance or had slight improvements.

\section{$\underline{\text { Unit Impact on Interest in Culturally Relevant Texts }}$}

This study generated some interest in further reading of culturally relevant literature. Post-unit, 50\% of students responded that they would like to read more books like this in school, with another 33\% responding "maybe" or "I don't know." Three students, or $16 \%$, responded that they "didn't care" or "no". When asked if the way they think about and select books to read has changed, only a few students, 4 of 20, 
specifically wrote about cultural elements becoming more important to them. A majority of student responses did mention a growing awareness of how to select books, which suggests that the study helped build student metacognition regarding the manner in which they select books. Four students indicated that no shift occurred, with three specifically writing that they did not care about the culture or language within a book. One Caucasian student, Katie, specifically noted that she made sure, "it doesn't relate to me because that is fun." She did, however, reveal a growing awareness for diversity within books, stating she would check to "make sure all cultures are seen."

Reviewing student preferences for cultural elements in books provides insight into the unit's impact on interest and mirrors the aforementioned results. Few students changed from disagreeing to agreeing in the six-week unit, but the majority of students did have a shift in response. When these results are taken in aggregate, as seen in table two, the unit appears to have resulted in a slight positive shift in students' preference for culturally relevant factors in books that they read. Sixty percent of students had a positive shift in placing importance on gender. The same percent, although not exactly the same students, also had a positive shift in gender preference. Half of students had a positive shift in importance of time period, whereas only one student had a negative shift in importance of time period (disagree to strongly disagree.) Forty-five percent of students had a positive shift in time period preference, and one student did have a negative shift in time period preference. Half of students had a positive shift in importance of race/ethnicity of character, whereas one student had a negative shift in importance of race/ethnicity. Finally, $40 \%$ of students had a positive shift in preference for 
race/ethnicity of character, whereas $10 \%$ of students had a negative shift in preference for race/ethnicity of character.

Survey data therefore reveals the unit generated some future interest in culturally relevant texts, an awareness for students on how to select texts, and a mild positive effect on how students view cultural elements as important in their reading material.

\section{Table 1.2 Positive Shifts in Cultural Preferences}

\begin{tabular}{|l|l|l|}
\hline Cultural Elements & & Positive Shift of One or More Likert Response \\
\hline Gender & Important & $60 \%$ \\
\hline & Prefer & $60 \%$ \\
\hline Time Period & Important & $50 \%$ \\
\hline Race/Ethnicity & Prefer & $45 \%$ \\
\hline & Important & $50 \%$ \\
\hline & Prefer & $40 \%$ \\
\hline
\end{tabular}

Summary of Results

In the initial stages of the study, students were able to increase their understanding of culture and identify their significant cultures for use in the study, which did not necessarily match ethnic/racial backgrounds. Students identified that most cultures, with the except of male and Caucasian, were underrepresented or outright missing in the examined seventh grade novel options. By way of curating books, utilizing book previews, and filtering them through cultural relevancy rubrics, a process for students to select culturally relevant novels was developed. This process resulted in $67 \%$ of students finding a "somewhat" to "highly relevant" novel for the unit. During literature circles and 
concluding projects, students successfully critiqued the cultural consciousness of the books they selected. According to survey data, students were not ranking culturally relevant factors as reasons for selecting a text pre-unit, and therefore were not consciously evaluating texts for cultural relevancy. Post-unit, students gave more importance to a book having similar characters or setting when ranking reasons for book selection. Post-unit preferences and importance placed on gender, ethnicity, and location of a novel also showed small positive shifts in student responses. 


\section{CHAPTER FIVE: DISCUSSION \& RECOMMENDATIONS}

The purpose of this study was to explore a process for finding culturally relevant literature for the secondary classroom and track its impacts on engagement, interest, and achievement. In the following discussion, the efficacy of the process is explored and its implications for future use in the classroom. The remainder of the discussion section is organized under a series of headings that reflect subtopics within the study.

\section{Literature Availability}

In reviewing the results of this study, one factor emerges as the most significant determining factor for the success of the process and unit: the access and availability of texts. Before students could predict relevancy, rank selection factors, or critique a novel's cultural consciousness, students and teacher had to use the materials that were available. Those materials were inadequate. A more ideal situation to assess the elements examined in this study would include materials that had an increase in thematic diversity, overall quality, and a greater number of books.

Another limiting factor encountered was a lack of deep knowledge of the books that were available. As students suggested, selection of relevant materials would be more accurate if a librarian or teacher, with deep knowledge of the novels, could act as a liaison between the books and students. The better knowledge of a book, the better chance a student would have to choose it as a culturally relevant novel. Similarly, finding culturally relevant novels requires intense curating. So why aren't culturally relevant book lists commonplace? One of the challenges of this study was simply finding lists in 
order to synthesize recommendations into a useable format. Accordingly, access to book lists are an important starting point for teachers and librarians who would like to incorporate more culturally relevant texts into the curriculum. To conclude, the likelihood of a student finding a culturally relevant novel depends on the availability and accessibility of diverse, conscious texts. Students can't select the books if they aren't in the library, nor can they read culturally relevant books if they don't know about them. And teachers can't showcase and promote culturally relevant books if they don't have access to them or deep knowledge of them.

\section{Initial Stages of the Study}

Looking beyond the significant constraints of text availability and text knowledge, the methods used to critique the curriculum and build cultural awareness were very successful. The critique chart (see appendix C) took the complexity of cultural relevancy and simplified it so that students could assess relevancy with overall ease. The exception to this involved two questions that students found challenging to answer in a short period of time: whether the text had similar experiences, or had characters similar to the student or student's family. Student capability to answer those two questions accurately, then, was likely diminished. Nonetheless, the curriculum critique highlighted to students that few students were offered mirrors within the literature. Although students clearly understood who was and was not represented, no student reflections on that information were observed. Since it was not witnessed in this study, how might students have felt about seeing how little their cultures were represented? Future research could explore student reactions to seeing how little representation they have in the curriculum. 


\section{Representation of Cultural Identity}

As students noted their significant cultures, one surprise was that no Caucasian students noted race/ethnicity as a significant culture, while all students of color did. Based on these results and student prior comments about "having no culture", it's likely that these Caucasian students did not see their ethnicity as culture. This invisibility of White American culture is not uncommon, and is reinforced by the multitude of what Bishop (1982) refers to as colorblind or melting pot texts, which whitewashes cultures in secondary literature classrooms. Given students' sociocultural development at this age, I wonder how to help students navigate understanding that White American culture varies from the experiences of people of color in America. A second point of interest occurred when looking at these results. The appearance of religion, notably Christianity, emerged as a significant culture for students. Being a public educator, I have been trained to avoid religion in the classroom. Yet according to the results on this study, the presence of religion could increase the cultural relevancy for a portion of students in a classroom.

As middle school initiates new identity-making, it is important to acknowledge the variability in the ways young adolescents connect to and label their identity. For the seventh grade participants in this study, time and activities were necessary in order for students to recognize how they could identify with their significant cultures. And while it was essential for the purposes of the study for students to pinpoint one or more significant culture(s), it must be taken into consideration that students this age are learning how to identify themselves in the world. It is thus possible students may not have as strongly identified with cultural signifiers as much as older secondary students might. Conversely, it's possible that the three specific cultural markers analyzed - 
gender, race, and location- were not of great importance to the identity of some students, as Sleeter (2008) and Sciurba (2014) commented on. It is also likely that this literature unit was the first time students had been asked to see and look critically at their culture and how their culture is represented. In addition, it is possible that embarrassment or shame may have prevented some students with identifying with certain cultural indicators, as a way to resist realities of poverty, prejudice, or violence. It is unknown how these factors likely influenced the outcomes of the study; continued research in this area, particularly focusing on secondary schools and adolescents, is required in order to understand those relationships.

\section{The Selection Process and Relevancy Rubrics}

The process of using book previews and cultural relevancy rubrics to sort and filter novels was an efficient method at introducing students to potentially relevant novels. One tension that existed in this process was how to group novels for students. Ultimately, I loosely divided them by gender and race, and organized the activity by grouping students around those sets based on what they wrote about in their cultural xrays. Even though students were invited to move between tables, and did so, it was somewhat problematic to predetermine groups, as it segregated both the novels and students. A better solution might have been to group books, but not students. Students could then instead roam without initial grouping, even though that would require additional time. Another way to improve this process, as aforementioned, could include the presence of a book broker- a librarian or teacher with deep knowledge of potentially relevant texts. This would likely improve student accuracy in making predictions on the 
novel's relevancy, which is a crucial component in reducing the $30 \%$ of students that did not make accurate predictions about their novels.

The book preview and selection process showed how essential student input is for incorporating culturally relevant material into the classroom. While I initially positioned students according to gender and race in books, gender and race were not always predictors of student selection. On the other hand, giving students choice means competing factors do come into play. For some students, this meant giving preference to novels that their friends were going to read, knowing that it would increase their peer interaction through-out the unit. For a few male students, finding texts that had violence or swearing piqued their interest enough to select those books over others. There are a number of ways this book preview process could be modified for similar pedagogical uses. For example, the process could be conducted at the start of school so that students could choose novels that they found more relevant for the year. Alternatively, it could guide student selection for independent reading books. Any use of this process would likely increase the visibility and selection of culturally relevant texts in the classroom.

\section{Critical Literacy with Culturally Relevant Novels}

One of this study's ancillary goals was to pair culturally relevant literature with critical literacy. Although only a fraction of the unit was spent on critical literacy discussions, student ability to become critical of cultural consciousness and power in literature shows promise for the success of continuing such work with middle school students. Some topics, such as realism in a novel, were easier for students to identify and discuss, whereas others needed further explanation than I anticipated. It may have been the first time students had ever been asked to look at these elements, so frequent 
examples of culture, cultural bias, imbalance of power between characters, etc. were needed in order for students to begin identifying these elements in what they were reading. For example, students often had to hear at least one teacher example and one student example of cultural bias in a novel before they recognized that same element in their reading and raised their hands to share out. Tasks such as placing a definition of cultural relevancy was placed on the wall, or explaining terms such as "voice" and "power" as having figurative meanings also assisted students in their work to critical analyze the texts.

\section{Data Collection Methods}

The use of survey data was instrumental in generating key information for the study, including ethnic/racial background, book selection reasoning, genre interest of students, and preferences for culturally relevant factors. There are a few ways, however, that the surveys could be refined to increase validity and clarity of results. First, the formatting for the survey question asking students to rank selection reasoning needed to be changed so that students cannot use a ranking more than once, as some did. Secondly, several questions on the survey probed general reading behavior, but the resulting data was not useful for answering the main questions of this research and thus could be removed. Thirdly, two questions should have been rewritten on Part II of the survey (see appendix B), in order to reduce confusion and redundancy. Additionally, one question was omitted and later added on to the Part II survey: a multiple choice on whether students thought their book was culturally relevant. Since data shows some students were confused what constituted as a culturally relevant novel, a definition should have been provided when asking students if they considered their novel relevant. The survey could 
also have asked students to explain their answer to that question. Furthermore, just as students completed a relevancy rubric during the book preview, they could have been asked to complete it again after finishing the novel; this would have allowed for more detailed data on accuracy of predicting the relevancy of a text. Finally, future similar studies would benefit by conducting student interviews, as Brooks (2006) did in her case study.

\section{Engagement and Achievement}

In building a literature unit that emphasized student choice and social constructivism, a challenge emerged in attempting to distill the impacts of culturally relevant literature on engagement from that of choice and social learning. This is complicated by the fact that without student choice in this process, cultural relevancy would be reduced for some and nonexistent for others. Ultimately, all three aspects likely interacted to increase engagement during this study. The engagement was consistently highest at the start of the unit, when students were involved in discussions on culture, critiquing the curriculum, and filtering culturally relevant novels for reading. During the reading unit, engagement continued to present itself in the quality of conversations between students. The neutral or slightly positive increase in turn-in rates supports the idea that the unit was not decreasing engagement. The quality of written work showed no significant differences from prior years, which could be looked at in one of two ways. One mitigating factor is that a portion of students read at a pace slower than what was required, which decreased the amount of time those students had in class to complete their write-ups. It is also possible that the richness of documented conversation did not translate to written 
work, or that the written tasks simply did not engage students in the same way as peer-led discussion.

One unmeasured factor that could have impacted results during this unit is student apathy towards school. While results show students were often engaged, data hints at some disengagement, such as an unwillingness to look for better fitting books, or a few students indicating that they didn't care to read similar books. Another consideration is how engagement in learning can be seen as uncool for some groups of students. This appeared within one literature circle of Latino boys. When asked about if they liked the book, they initially responded negatively or ambivalently, with one boy saying, "This book is like all others: it has words and pages." Yet as I asked them one by one to rate the novel, all but one boy rated the book a 7 or 8 . The last student shrugged in agreement, and his peer outed him, by saying, "Oh he liked the book." So initially these students had reservations about expressing positive attitudes towards the book, and one was called out for liking it. It wasn't until shifting the conversation that they showed their interest and criticism for the book. From this example, it can be seen that the "cool" factor of reading may influence the way some students respond in front of their peers regarding their attitudes towards reading, and reinforces the idea that the method of asking a question may greatly influence the way a student will answer it.

\section{Preferences and Interest in Culturally Relevant Literature}

When students were asked if they were interested in reading more books like the ones in the literature unit, a significant portion were ambivalent about it. Yet if over onethird of students didn't find a culturally relevant novel, it is not surprising that over onethird of students were ambivalent about reading more in the future. At least two students 
suspected that their novels weren't relevant soon into the unit, but didn't attempt to find a different book. This sequence is not surprising given that those students didn't feel there were many options for them in the first place. Disinterest or am bivalency may have, in party, been the result of low quality, low relevancy novels. General apathy towards school, as mentioned above, could also impact students' eagerness to read more books like those read in the unit; it is feasible that some students interpreted the question as, "Do you want to read more books?" versus, "If you were to choose the type, would you want books like these?" A Likert scale question could help clear this ambiguity.

Data shows that students were not selecting texts for culturally relevant factors prior to the literature unit, which slightly shifted when the unit had concluded. A set of variables exist that could explain how and why students were not selecting texts for culturally relevant factors. First, it is likely that students, particularly students of color, had limited or no prior exposure to culturally relevant texts. Students might simply not have known that such books exist in order to seek and select them. Additionally, prior knowledge of culture and cultural representation, and the degree of cultural identification all could have also influenced the results both pre-unit and post-unit. During the literature unit, the quality of texts representing cultural relevancy likely impacted how students would or would not come to prefer these factors. Lastly, it is possible, although unobserved in this study, that student response on the survey questions regarding reading preferences could have been influenced by stigma against expressing bias on gender and race. If students thought they might be seen in a negative light for preferring those commonalities in their reading, it is possible that some would respond in a way that would reflect on them more favorably. 


\section{Data for Future Research}

Three topics not fully examined in the scope of this study are presented here as areas worth exploring by future researchers. Initially, this study sought to explore how often students experience literature that mirrors their own cultures. It is clear that examined curriculum novels did not offer students the opportunity to experience such literature. Nor, for the most part, did the school libraries, where such texts were difficult to find. Indeed, Martinez (2013) confirms that schools across the area lack culturally rich novels within their libraries. It can be postulated that students' rarely have access to culturally relevant literature in order to experience literature mirroring their own culture based on these items, but more evidence is needed to substantiate this claim. Looking at it from another angle, the school librarian anecdotally stated that she had never had a student ask specifically for that type of book. Yet the book previews generated interest in numerous relevant books that weren't selected by students for the unit. Research could be conducted to assess frequency of exposure according to student perspectives or teacher perspectives and the impact this has on students and their reading behaviors, attitudes, and performance. Increasing access and visibility in libraries could also be looked at as an instigator for increasing student exposure to culturally relevant literature.

The second set of data involves survey data which offered a look into cultural identity awareness. Similar to how Robbins' (2001) saw student self-identification grow, the pre- and post-unit comparison data shows a mild positive shift in student cultural identity awareness and belonging. While the majority of students agreed and maintained having pride in their ethnic group, 7 out of 20 students showed an increase in pride for their ethnic group. Another 8 of 20 students had an improved sense of their ethnic 
background and what it means to them. A number of activities within the unit may have had a positive impact on students' cultural awareness, such as defining and expanding definitions of culture or critical literacy activities, which critiqued cultural representation.

Thirdly, the process students took to filter and select culturally relevant literature appears to have increased metacognition about book selection. Numerous students wrote about how the way they select books had changed. Elements that students noted as becoming less important in their selection process include the title and book cover, whereas genre or theme became more important. It is possible that the process of asking students to choose and justify their responses, with the addition of answering surveys about how they selected books, increased student reflection on their own processes. The use of the book preview and the corresponding literature unit may have increased student exposure to a variety of novels, which in turn may have assisted in refining their selection process as well.

\section{Conclusion}

At the beginning of this research, I sought to explore how culturally relevant literature, once introduced, might matter to students. Only pieces of this answer have been uncovered in the analysis conducted in this study. What can be said is that the brief unit undoubtedly sparked student thinking on representation in books, and how those books relate to their own culture and experiences. Long after this study concluded, the imprint of critical literacy in the literature classroom could still be seen. During book talks in the final days of school, one student raised his hand to initiate a discussion on race in independent reading. His question, "What is the race of the main character?" prompted his peers to continue considering the role of race and representation in novels. 
In doing so, he reminded his peers of an increased expectation of how to think about and critique literature, by looking for culturally diverse and culturally significant factors in their own reading.

\section{Recommendations}

The following recommendations are given to improve the selection process and presence of culturally relevant texts in secondary classrooms:

- Encourage librarians to purchase award-winning, culturally relevant books by authors of color and display them.

- Increase teacher awareness of culturally conscious texts.

- Improve the curriculum selection process so that novels are assessed for cultural consciousness and diversity. Ask curriculum reviewers to give preference to culturally relevant texts during curriculum selection until the curriculum reflects the diversity of the school and surrounding community.

- Support student choice with student-guided literature circle units.

- Expand research at the secondary level on culturally relevant literature and its affects on achievement, engagement, and interest for secondary students. 


\section{REFERENCES}

Au, K. H., \& Kawakami, A. J. (1994). Cultural congruence in instruction. In E. R. Hollins, J. E. King, \& W. C. Hay- man (Eds.), Teaching diverse populations: Formulating a knowledge base (pp. 5-23). Albany: State University of New York Press.

Bishop , R. S. (1990). Mirrors, windows, and sliding glass doors. Perspectives: Choosing and Using Books for the Classroom, 6 ( 3 ).

Bishop, R. S. (2012). Reflections on the development of African American children's literature. Journal Of Children's Literature, 38(2), 5-13.

Brooks, W. (2006). Reading representations of themselves: Urban youth use culture and African American textual features to develop literary understandings. Reading Research Quarterly, 41(3), 372-392. doi:10.1598/RRQ.41.3.4

Camangian, P. R. (2015). Teach like lives depend on it: Agitate, arouse, and inspire. Urban Education, 50(4), 424-453. doi:10.1177/0042085913514591

Cazden, C., \& Leggett, E. (1981). Culturally responsive education: Recommendations for achieving Lau remedies II. In H. Trueba, G. Guthrie, \& K. Au (Eds.), Culture and the bilingual classroom: Studies in classroom ethnography (pp. 69-86). Rowley, MA: Newbury. 
Cisneros, S. (1989). The house on mango street. Houston, Tex: Arte Publico Pr.

Dressel, J. H. (2005). Personal response and social responsibility: Responses of middle school students to multicultural literature. Reading Teacher, 58(8), 750-764. doi:10.1598/RT.58.8.5

Ebe, A. E. (2010). Culturally relevant texts and reading assessment for English language learners. Reading Horizons, 50(3), 193-210.

Ebe, A. E. (2012). Supporting the reading development of middle school English language learners through culturally relevant texts. Reading \& Writing Quarterly, 28(2), 179-198. doi:10.1080/10573569.2012.651078

Erickson, F., \& Mohatt, G. (1982). Cultural organization and participation structures in two classrooms of Indian students. In G. Spindler (Ed.), Doing the ethnography of schooling (pp. 131-174). New York: Holt, Rinehart \& Winston.

Feger, M. (2006). I want to read: How culturally relevant texts increase student engagement in reading. Multicultural Education, 13(3), 18-19.

Fogarty, M. S., Myint, A., Davis, J. L., \& Anderson, L. L. (2017). Using relevance prompts: An exploratory study to promote eighth graders' comprehension and retelling of narrative text. Literacy Research \& Instruction, 56(1), 54-67. doi:10.1080/19388071.2016.1219927

Freeman, Y. S, Freeman, A. E., \& Freeman, D. E. (2003). Home run books: Connecting students to culturally relevant texts. NABE News, 26(3), 5-12, 28.

Freeman, Y. S., \& Freeman, D. E. (2004). Connecting students to culturally relevant texts. Talking Points, 15(2), 7-11. 
Freire, P., \& Macedo, D. (1987). Literacy: Reading the word and the world. Westport, CT: Bergin \& Garvey.

Garcia, G. E. (1991). Factors influencing the English reading test performance of Spanish-speaking Hispanic children. Reading Research Quarterly, 26(4), 371-92.

Garza, C. L. (1995). Family pictures =: Cuadros de familia. Carson, Calif.: Lakeshore Learning Materials.

Gay, G. (2002). Preparing for culturally responsive teaching. Journal Of Teacher Education, 53(2), 106-116.

Gibson, S. (2010). Critical readings: African American girls and urban fiction. Journal Of Adolescent \& Adult Literacy, 53(7), 565-574.

Goodman, Y. M. (1982). Retellings of literature and the comprehension process. Theory Into Practice, 21(4), 301.

Gray, E.S. (2009). The importance of visibility: Students' and teachers' criteria for selecting African American literature. The Reading Teacher, 62(6), 472.

Guthrie, J. T. (2001). Benefits of opportunity to read and balanced instruction on the NAEP. Journal Of Educational Research, 94(3), 145.

Hall, E. T. (1976). Beyond culture. Garden City, NY: Anchor Press.

Heath, Shirley Brice. (1991). The sense of being literate: Historical and cross-cultural features. In R. Barr et al (Eds.), Handbook of Reading Research, Volume II (Pp.3-25). NY: Longman Publishing Group.

Herrero, E. A. (2006). Using Dominican oral literature and discourse to support literacy 
learning among low-achieving students from the Dominican Republic.

International Journal of Bilingual Education \& Bilingualism, 9(2), 219-238.

Hobbs, W. (2007). Crossing the wire. HarperTrophy: New York.

Hulleman, C. S., \& Harackiewicz, J. M. (2009). Promoting interest and performance in high school science classes. Science, 326, 1410-1412. doi:10.1126/science.1177067

Hussar, W.J., and Bailey, T.M. (2016). Projections of education statistics to 2023 (NCES 2015-073). U.S. Department of Education, National Center for Education Statistics. Washington, DC: U.S. Government Printing Office. Irvine, J. (1990). Black students and school failure. Westport, CT: Greenwood Jiménez, F. (1997). The circuit: stories from the life of a migrant child. Albuquerque, New Mexico: University of New Mexico Press.

Jiménez, F. (2001). Breaking through. Boston: Houghton Mifflin.

Jimenez, R. T. (1997). The strategic reading abilities and potential of five low-literacy Latina/o readers in middle. Reading Research Quarterly, 32(3), 224.

Kelley, H. M., Siwatu, K. O., Tost, J. R., \& Martinez, J. (2015). Culturally familiar tasks on reading performance and self-efficacy of culturally and linguistically diverse students. Educational Psychology In Practice, 31(3), 293-313.

Ladson-Billings, G. (2014). Culturally relevant pedagogy 2.0: A.k.a. the remix. Harvard Educational Review, 84(1), 74-84.

Ladson-Billings, G. (1995). Toward a theory of culturally relevant pedagogy. American Educational Research Journal, 32(3), 465-491. 
Luke, A. (2000). Critical literacy in Australia: A matter of context and standpoint. Journal of Adolescent \& Adult Literacy, 43(5), 448-461

Ma'ayan, H. D. (2010). Erika's Stories: Literacy solutions for a failing middle school student. Journal Of Adolescent \& Adult Literacy, 53(8), 646-654.

Martínez, María Elena (2013) "A Study of the Availability of Multicultural Children's Literature in Treasure Valley Schools: Quality, Access and Inclusion," McNair Scholars Research Journal: Vol. 9 : Iss. 1 , Article 11. Available at: http://scholarworks.boisestate.edu/mcnair_journal/vol9/iss1/11

Medina, J. (1999). My name is Jorge on both sides of the river. Honesdale, PN.: Wordsong/Boyds Mills Press.

Morrell, E. (2009). Commentary: Critical research and the future of literacy education. Journal Of Adolescent \& Adult Literacy, 53(2), 96-104.

Ouimet, Alysse, (2011). Culturally relevant literature How to identify and use culturally relevant literature. Education Masters. Paper 15. Retrieved from http://fisherpub.sjfc.edu/education_ETD_masters/15

Padron, Y. N., Waxman, H. C., Rivera, H. H., \& Center for Research on Education, D. C. (2002). Educating Hispanic Students: Obstacles and Avenues to Improved Academic Achievement. Educational Practice Report 8.

Robbins, C. (2001). "Por Que Soy Tonto?” Exposing "invisible" interactions in a (n) multi- racial (American) classroom. The Radical Teacher, 60, 22-26.

Roberts, R. E., \& Phinney, J. S. (1999). The structure of ethnic identity of young adolescents From Diverse Ethnocultural Groups. Journal Of Early 
Adolescence, 19(3), 301.

Rodríguez, A. D. (2009). Culturally relevant books: Connecting Hispanic students to the curriculum. GiST Colombian Journal of Bilingual Education, 3, 11-29.

Schiefele, U., Schaffner, E., Möller, J., Wigfield, A., Nolen, S., \& Baker, L. (2012). Dimensions of reading motivation and their relation to reading behavior and competence. Reading Research Quarterly, 47(4), 427-463. doi:10.1002/RRQ.030

Sciurba, K. (2014). Texts as mirrors, texts as windows. Journal Of Adolescent \& Adult Literacy, 58(4), 308-316. doi:10.1002/jaal.358

Scribner, A. P., Scribner, J. D., \& ERIC Clearinghouse on Rural Education and Small Schools, C. W. (2001). High-Performing Schools Serving Mexican American Students: What They Can Teach Us. ERIC Digest.

Short, K. G. (2009). Critically reading the word and the world: Building intercultural understanding through literature. Bookbird: A Journal of International Children's Literature 47(2), 1-10. The Johns Hopkins University Press.

Siegel, M., \& Fernandez, S. L. (2000). Critical approaches. In M. L. Kamil, P. D. Pearson, R. Barr \& P. B. Mosenthal (Eds.), The handbook of reading research (Vol. III, pp. 141-152). Mahwah, NJ: Lawrence Erlbaum.

Sims, R. (1982). Shadow and substance: Afro-American experience in contemporary children's fiction. Urbana, IL: National Council of Teachers of English.

Sleeter, C. E. (2008). Involving students in selecting reading materials. In M. Pollock (Ed.), Everyday antiracism: Getting real about race in school (pp. 150-153). New York, NY: The New Press. 
APPENDIX A 


\section{Reading Choices Survey Part I}

Instructions: Complete the form to the best of your ability. You may choose to skip questions.

What is your age?

- 11

- 12

- 13

- 14

What is your gender?

- Female

- Male

- Other/ prefer not to answer

In this country, people come from many different countries and cultures, and there are many different words to describe the different backgrounds or ethnic groups that people come from. Some examples of the names of ethnic groups are Hispanic or Latino, Black or African American, Asian American, Chinese, Filipino, American Indian, Mexican American, Caucasian or White, Italian American, and many others.

What do you consider your race or ethnic group?

- White/Caucasian

- Black/African American

- Hispanic, Latino, or Spanish origin

- American Indian or Native Alaskan

- Native Hawaiian or Pacific Islander

- Some other race or origin

Indicate how much you agree or disagree with each of the following statements:

I am active in organizations or social groups that include mostly members of my own ethnic group.

Strongly agree Agree Disagree Strongly disagree

I have a clear sense of my ethnic background and what it means for me.

Strongly agree Agree Disagree Strongly disagree

I have a lot of pride in my ethnic group.

Strongly agree Agree Disagree Strongly disagree

I participate in cultural practices of my own group, such as special food, music, or customs. 
Strongly agree Agree Disagree Strongly disagree

I understand pretty well what my ethnic group membership means to me.

Strongly agree Agree Disagree Strongly disagree

I feel good about my cultural or ethnic background.

Strongly agree Agree Disagree Strongly disagree

Please put a check beside those things you have read in the past week. Please think hard to remember it all:

- Emails

- Texts

- Books

- Articles online or in print

- Social Media (Twitter, Tumblr, Facebook)

- Other

Look over all that you checked above. How many hours did you spend doing all of it during the past week?

- Emails

- Texts

- Books

- Articles online or in print

- Social Media (Twitter, Tumblr, Facebook)

- Other

Reviewing your answers to question two, is this a typical week of reading for you?

- Yes

- No

- More than normal

- Less than normal

- Not Sure

Please select how much you agree or disagree with the following statements.

When I read, it is important to me that a main character is same gender as me.

- Strongly agree

- Agree

- Neutral

- Disagree

- Strongly disagree 
When I read, I would rather read a text with a main character the same gender as me.

- Strongly agree

- Agree

- Neutral

- Disagree

- Strongly disagree

When I read, it is important to me that the text takes place in the same time period as now.

- Strongly agree

- Agree

- Neutral

- Disagree

- Strongly disagree

When I read, I would rather read a text that takes place in the same time period as now.

- Strongly agree

- Agree

- Neutral

- Disagree

- Strongly disagree

When I read, it is important to me that the main characters that have the same race or ethnic background as me.

- Strongly agree

- Agree

- Neutral

- Disagree

- Strongly disagree

When I read, I would rather read a text with main characters that have the same race or ethnic background as me.

- Strongly agree

- Agree

- Neutral

- Disagree

- Strongly disagree

Rank the following reasons you use to select a book, from 1-most important to 7least important:

- Genre: The book is in a genre I like to read

- Illustrations: The book has drawings and illustrations

- Cover of book: Cover of book makes it look good

- Looks easy to read 
- Has characters or setting similar to mine

- Other

Recommended to me

Please check all below that you like reading about.

(If you don't read often or not a reader, what types of movies, TV shows, or video games do you prefer?)

_ adventure/survival mystery/suspense

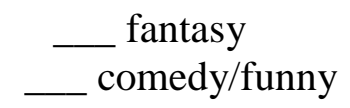

science

fiction horror romance/relationships history poetry realistic/reality fiction crime graphic novels health/wellness/fitness science _ art _ sports war technology

$\begin{array}{cc}\text { biography/autobiography } \\ \text { politics } \\ \text { music } & \text { How-To }\end{array}$

/Walkthroughs

Of all the categories above, which 3 are your favorites? 
APPENDIX B 


\section{Reading Choices Survey Part II}

1. When you first selected the novel to read, how did you think it would relate to you and your culture?

2. Now that you have finished the book, how did the book actually relate to you and your culture? (Please indicate if it did not and how, if that applies to your novel.)

3. Have your ideas on culture changed since the start of the unit? If yes, how have your ideas about culture changed since the start of the unit?

4. Has the way you select books to read changed since the start of the unit? If yes, how has the way to select books changed?

5. Has anything changed in the way you think about and select books to read?

6. What has become more important to you when selecting and reading books?

7. What has become less important to you when selecting and reading books? 
APPENDIX C 


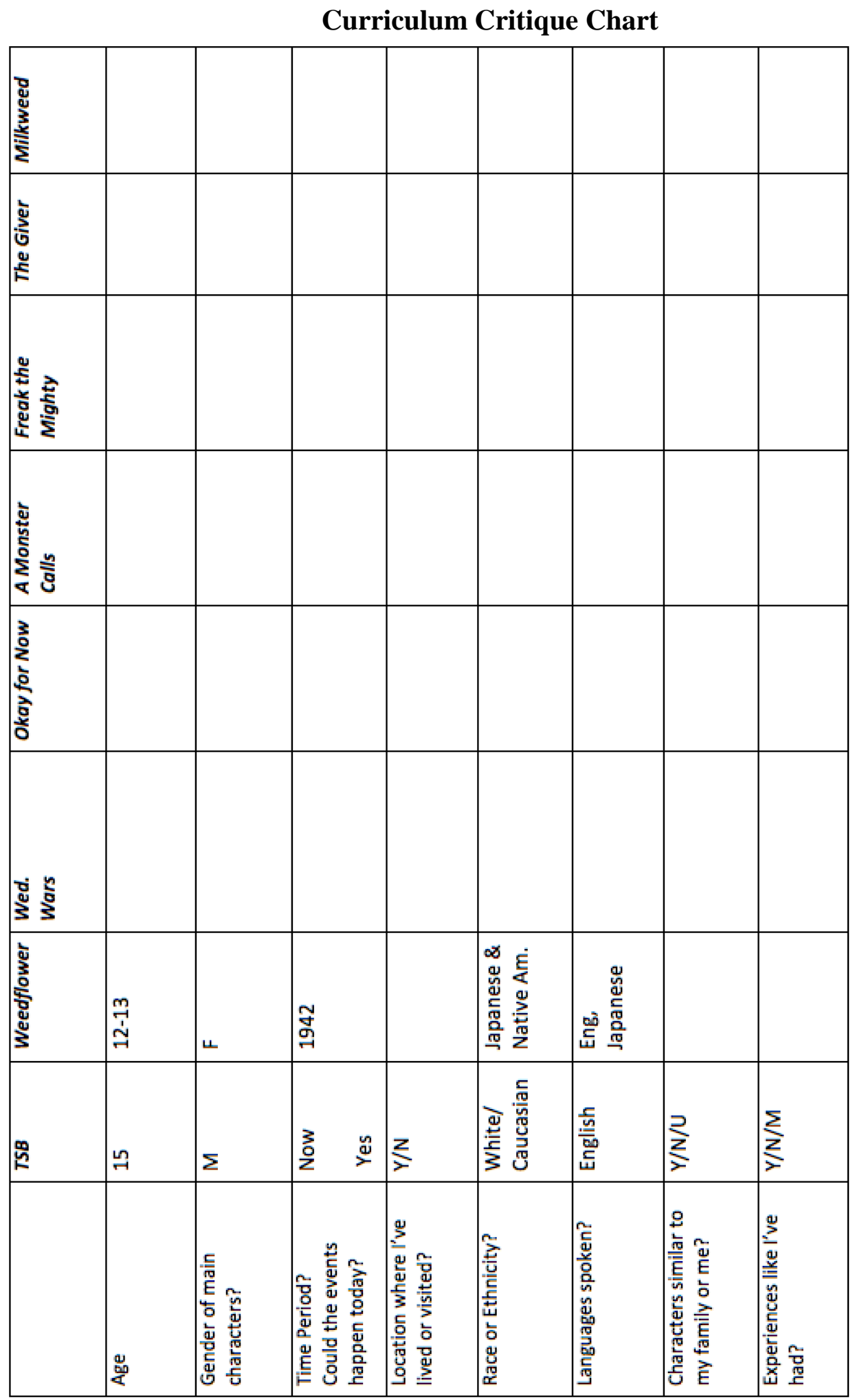

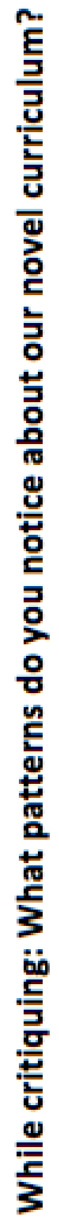




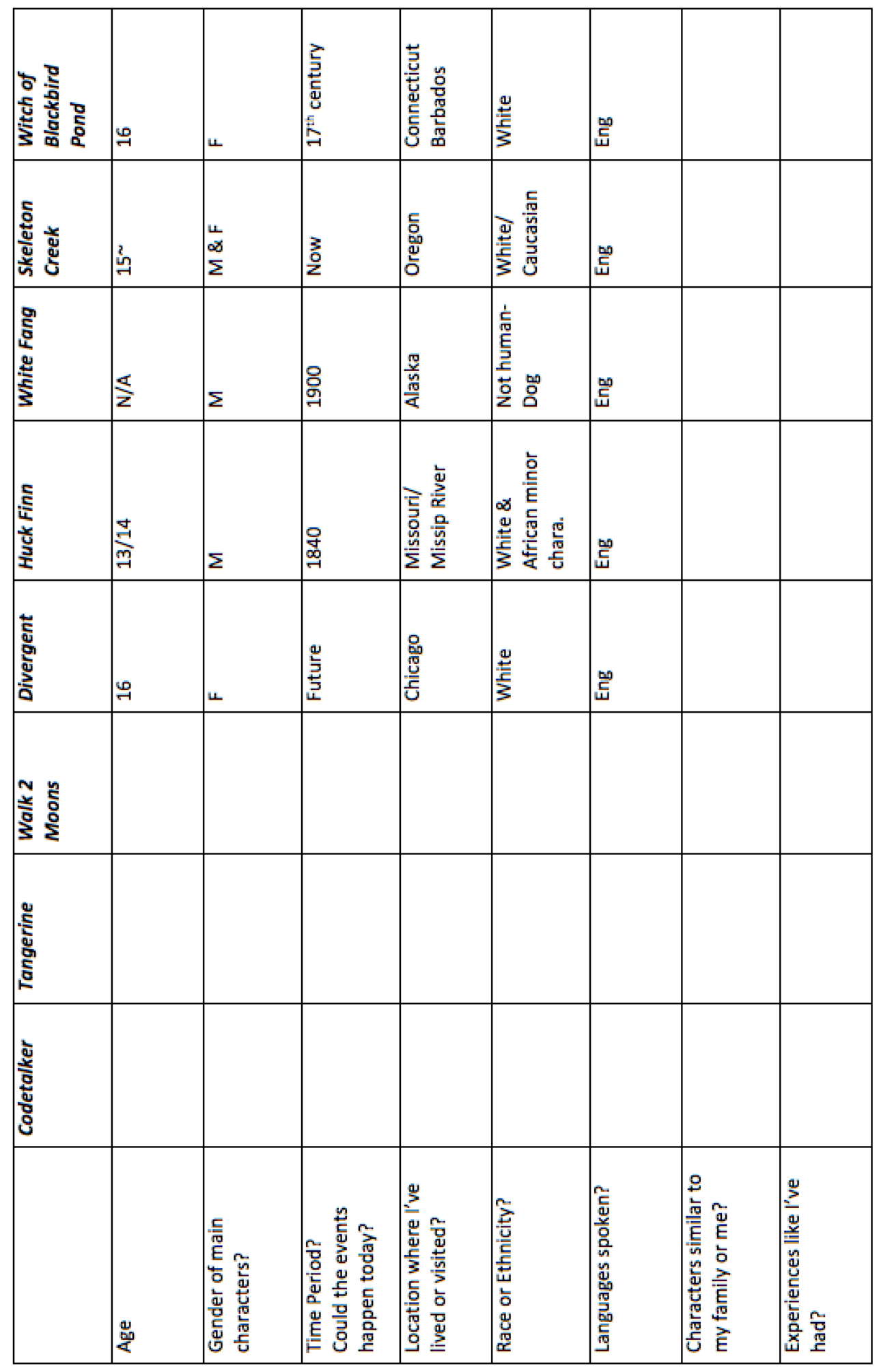

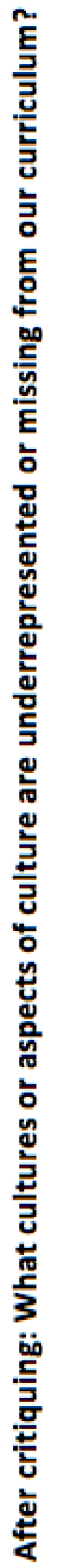


APPENDIX D 


\section{Cultural Relevancy Rubric}

The rubric was applied to each book a student previewed.

NAME:

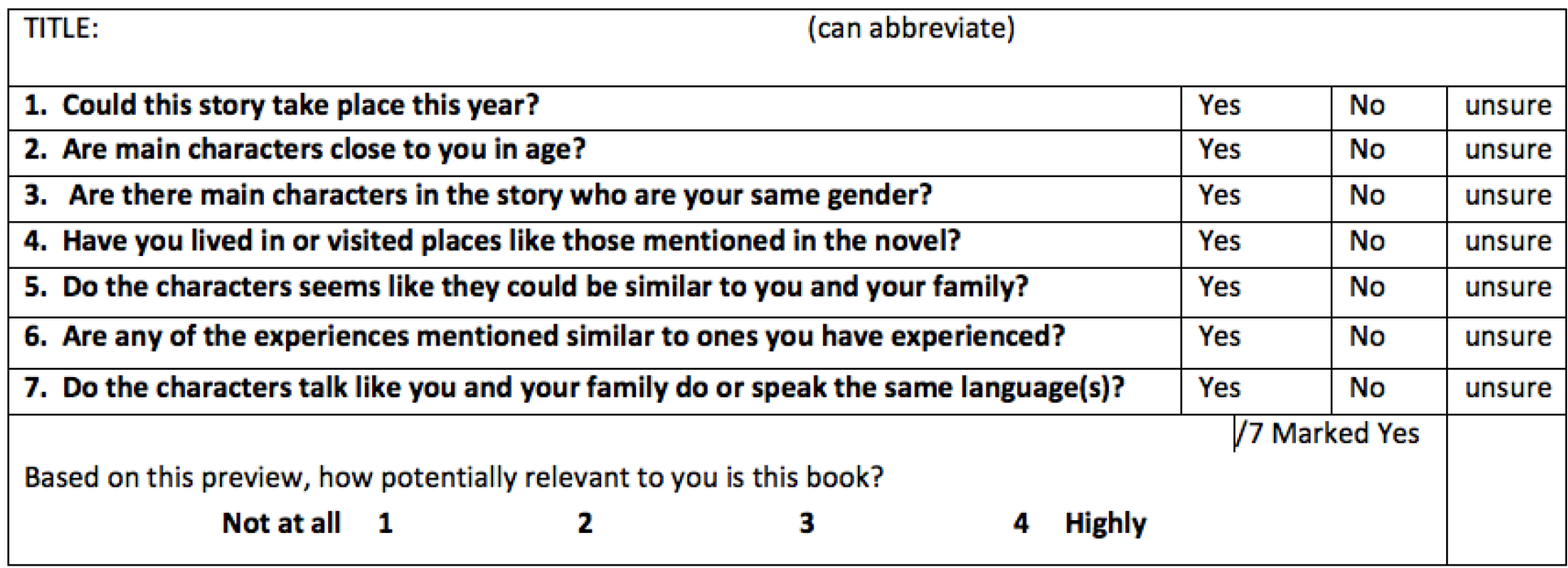




\section{Novel Selection Form}

NAME:

DATE:

After previewing all of the available books, my top three choices for the reading unit are:

1.

This book is my top choice because

2.

This book is my 2 nd choice because

3.

This book is my 3rd choice because 
APPENDIX E 


\section{Novels Used in Culturally Relevant Literature Unit}

Those bolded indicate recommendation for future use.

Adler, C. S. (2002). The no place cat. New York: Clarion Books.

Agell, C. (2003). Welcome home or someplace like it. New York: H. Holt.

Alvarez, J. (2002). How Tía Lola came to visit stay. NY, NY: Dell Yearling.

Arnold, E. K. (2015). The question of miracles. Boston: Houghton Mifflin

Harcourt.

Budhos, M. (2011). Tell us we're home. New, New: Atheneum Books for

\section{Young Readers.}

Chandler, K. (2011). Wolves, boys, \& other things that might kill me. Turtleback Books.

Chmakova, S. (2015). Awkward. New York, NY: Yen Press.

Connor, L. (2010). Waiting for normal. New York: Katherine Tegen Books.

Hemmings, K. H. (2016). Juniors. Penguin USA.

Hobbs, W. (2007). Crossing the wire. HarperTrophy: New York.

Jiménez, F. (2001). Breaking through. Boston: Houghton Mifflin.

Klass, D. (2016). Losers take all. New York, NY: Scholastic, Inc.

Lupica, M. (2012). The big field. New York: Puffin Books.

Lupica, M. (2014). Game changers. New York: Scholastic Inc.

Lupica, M. (2012). Travel team. New York: Puffin Books.

Myers, W. D. (2013). Scorpions. New York: Amistad / HarperCollins.

Soto, G. (2006). Buried onions. Orlando, FL: Harcourt.

Soto, G. (2006). Petty crimes. Orlando: Harcourt, Inc. 
Additional Books Cited in Literature for Cultural Relevancy

Cisneros, S. (1989). The house on mango street. Houston, Tex: Arte Publico Pr.

Garza, C. L. (1995). Family pictures =: Cuadros de familia. Carson, Calif.: Lakeshore Learning Materials.

Jiménez, F. (1997). The circuit: stories from the life of a migrant child. Albuquerque, New Mexico: University of New Mexico Press.

Medina, J. (1999). My name is Jorge on both sides of the river. Honesdale, PN.:

Wordsong/Boyds Mills Press. 